\title{
Micromotors for drug delivery in vivo: The road ahead
}

\author{
Srivastava, Sarvesh Kumar; Clergeaud, Gael; Andresen, Thomas L.; Boisen, Anja
}

Published in:

Advanced Drug Delivery Reviews

Link to article, DOI:

10.1016/j.addr.2018.09.005

Publication date:

2019

Document Version

Peer reviewed version

Link back to DTU Orbit

Citation (APA):

Srivastava, S. K., Clergeaud, G., Andresen, T. L., \& Boisen, A. (2019). Micromotors for drug delivery in vivo: The road ahead. Advanced Drug Delivery Reviews, 138, 41-55. https://doi.org/10.1016/j.addr.2018.09.005

\section{General rights}

Copyright and moral rights for the publications made accessible in the public portal are retained by the authors and/or other copyright owners and it is a condition of accessing publications that users recognise and abide by the legal requirements associated with these rights.

- Users may download and print one copy of any publication from the public portal for the purpose of private study or research.

- You may not further distribute the material or use it for any profit-making activity or commercial gain

- You may freely distribute the URL identifying the publication in the public portal

If you believe that this document breaches copyright please contact us providing details, and we will remove access to the work immediately and investigate your claim 


\section{Accepted Manuscript}

Micromotors for drug delivery in vivo: The road ahead

Sarvesh Kumar Srivastava, Gael Clergeaud, Thomas L. Andresen, Anja Boisen

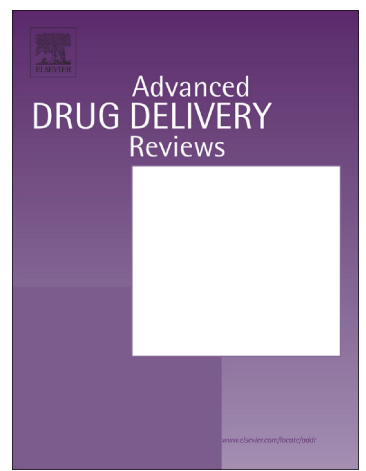

PII:

S0169-409X(18)30225-4

DOI:

doi:10.1016/j.addr.2018.09.005

Reference:

ADR 13373

To appear in:

Advanced Drug Delivery Reviews

Received date:

20 April 2018

Revised date:

27 August 2018

Accepted date:

11 September 2018

Please cite this article as: Sarvesh Kumar Srivastava, Gael Clergeaud, Thomas L. Andresen, Anja Boisen, Micromotors for drug delivery in vivo: The road ahead. Adr (2018), doi:10.1016/j.addr.2018.09.005

This is a PDF file of an unedited manuscript that has been accepted for publication. As a service to our customers we are providing this early version of the manuscript. The manuscript will undergo copyediting, typesetting, and review of the resulting proof before it is published in its final form. Please note that during the production process errors may be discovered which could affect the content, and all legal disclaimers that apply to the journal pertain. 


\section{Micromotors for Drug Delivery In vivo: The Road Ahead}

Sarvesh Kumar Srivastava*a ${ }^{\star}$ Gael Clergeaud ${ }^{\star b}$, Thomas L. Andresen ${ }^{\mathrm{b}}$, Anja Boisen $^{\mathrm{a}}$

${ }^{a}$ Center for Intelligent Drug delivery and sensing Using microcontainers and Nanomechanics (IDUN), Department of Micro- and Nanotechnology, Technical University of Denmark, Denmark

${ }^{\mathbf{b}}$ Center for Nanomedicine and Theranostics, Department of Micro- and Nanotechnology, Technical University of Denmark, Denmark

*Corresponding author: sarvesh.kumar@nanotech.dtu.dk; gaecle@nanotech.dtu.dk TOC:

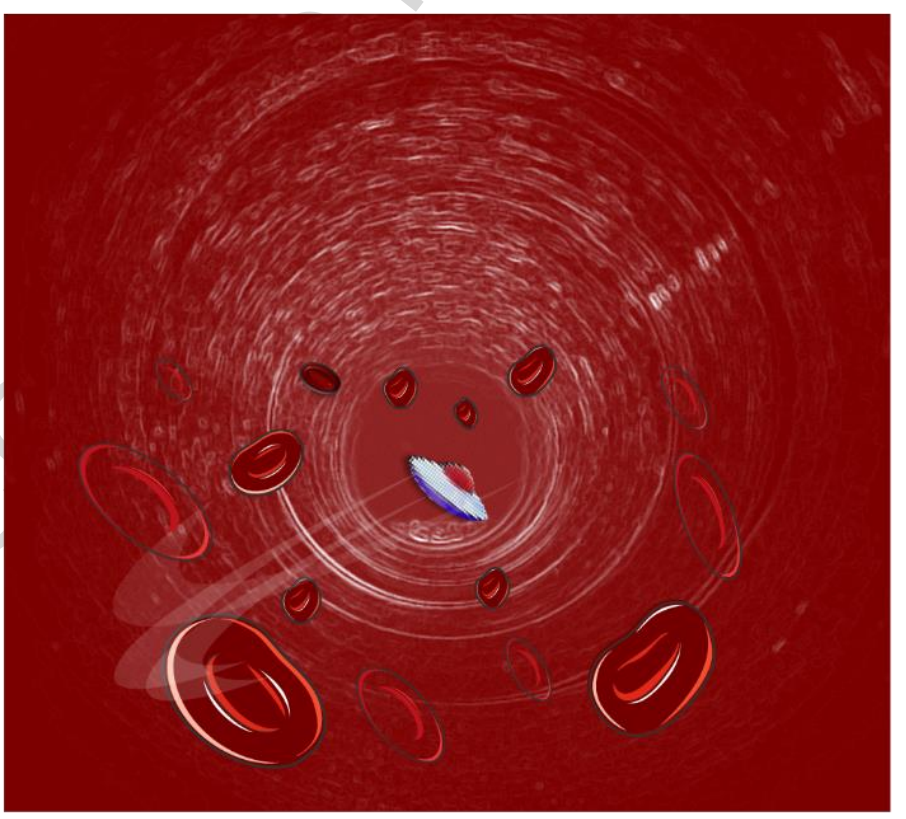

Micromotors in vivo: From sci-fi to clinical reality

Abstract: 
Autonomously propelled/externally guided micromotors overcome current drug delivery challenges by providing (a) higher drug loading capacity, (b) localized delivery (less toxicity), (c) enhanced tissue penetration and (d) active maneuvering in vivo. These microscale drug delivery systems can exploit biological fluids as well as exogenous stimuli, like light-NIR, ultrasound and magnetic fields (or a combination of these) towards propulsion/drug release. Ability of these wireless drug carriers towards localized targeting and controlled drug release, makes them a lucrative candidate for drug administration in complex microenvironments (like solid tumors or gastrointestinal tract). In this report, we discuss these microscale drug delivery systems for their therapeutic benefits under in vivo setting and provide a design-application rationale towards greater clinical significance.

Keywords: Micromotors, Drug Delivery in vivo, Gl tract, solid tumor, external trigger actuation Drug delivery systems (DDS) have not only promoted a novel generation of therapeutics like proteins/peptides (pharmaceuticals with short half-lives) or nucleic acids offering greater sitespecificity[1] but also better predictability of pharmacokinetic \& pharmacodynamic profiles of conventional drugs.[2] This has resulted in their improved biodistribution, decreased side-effects and enhanced therapeutic efficacy. Clearly, choice of a DDS is critical as (a) pharmacologically active agents are not inherently effective by themselves; (b) the efficacy of a drug is greatly influenced by the route and methodology of administration; and (c) drug pharmacokinetic properties can be greatly improved (especially for routes which have traditionally demonstrated poor impact).[3] For instance, oral administration of several drugs is hindered due to poor bioavailability owing to harsh gastrointestinal (GI) microenvironment [4] and destruction by liver enzymes (also known as first pass effect)[5]. In contrast, parenteral (intravenous, subcutaneous and intramuscular) forms of administration yield rapid effect with very high drug bioavailability but rather low patient compliance due to the discomforts involved in the process.[6] 
Another advantage of using a DDS over direct administration of active pharmaceutical ingredient (API)/drug, is to reduce the undesired toxic side-effects, thereby facilitating higher therapeutic doses and therapeutic index of the drug. This has particular relevance for cytotoxic drugs, like chemotherapeutics, which are very potent against cancer but also exhibit high toxicity towards healthy tissues (thereby, impeding their usage at clinically relevant doses/concentrations) $[7,8]$. This important medical need coupled with effective dosage requirement has created the need for site-specific drug delivery systems. Ideally, such a dynamic DDS should achieve therapeutic drug levels at the target site, limit exposure to healthy tissues, and consequently, minimize the occurrence of side-effects. This can be achieved by incorporating a "trigger switch" or "control mechanism" that facilitates drug release in the target tissue only under specific local or external stimuli. Based upon their stimuli-responsive behavior, DDSs can be divided into two broad categories: (a) endogenously triggered DDS (using $\mathrm{pH}$, redox microenvironment, ATP/glucose, enzymes and hypoxia, among others); and (b) exogenously triggered DDS, or externally actuated DDS (via temperature, light, magnetic fields and ultrasound). At this point, it is important to highlight that such synthetic, physically actuated or chemically propelled DDS have also been referred as nano/micromotors (depending upon their size scale) in certain scientific communities.[9][10] While several reviews can be found in the area of nano/micromotors for drug delivery discussing their in vitro and in vivo significance among others[11][12], the quintessential pharmacological perspective remains elusive from these reports.

Here in, we have made an effort to expand the discussion of microscale DDS in vivo, with by establishing a design-application relationship and associated pharmacological significance. Focus has been kept towards in vivo applications (see figure 1A) to create a common ground between chemical engineers, material scientists, clean-room experts, pharmacologists and clinicians, towards designing of clinically relevant solutions (i.e. clinical significance). Owing to a 
rather limited number of such studies, this review draws inspiration from the fundamentals in clinical drug delivery, discussing current challenges and opportunities, all done with an aim to provide a clear blueprint for micromotors technology towards translational drug delivery research.

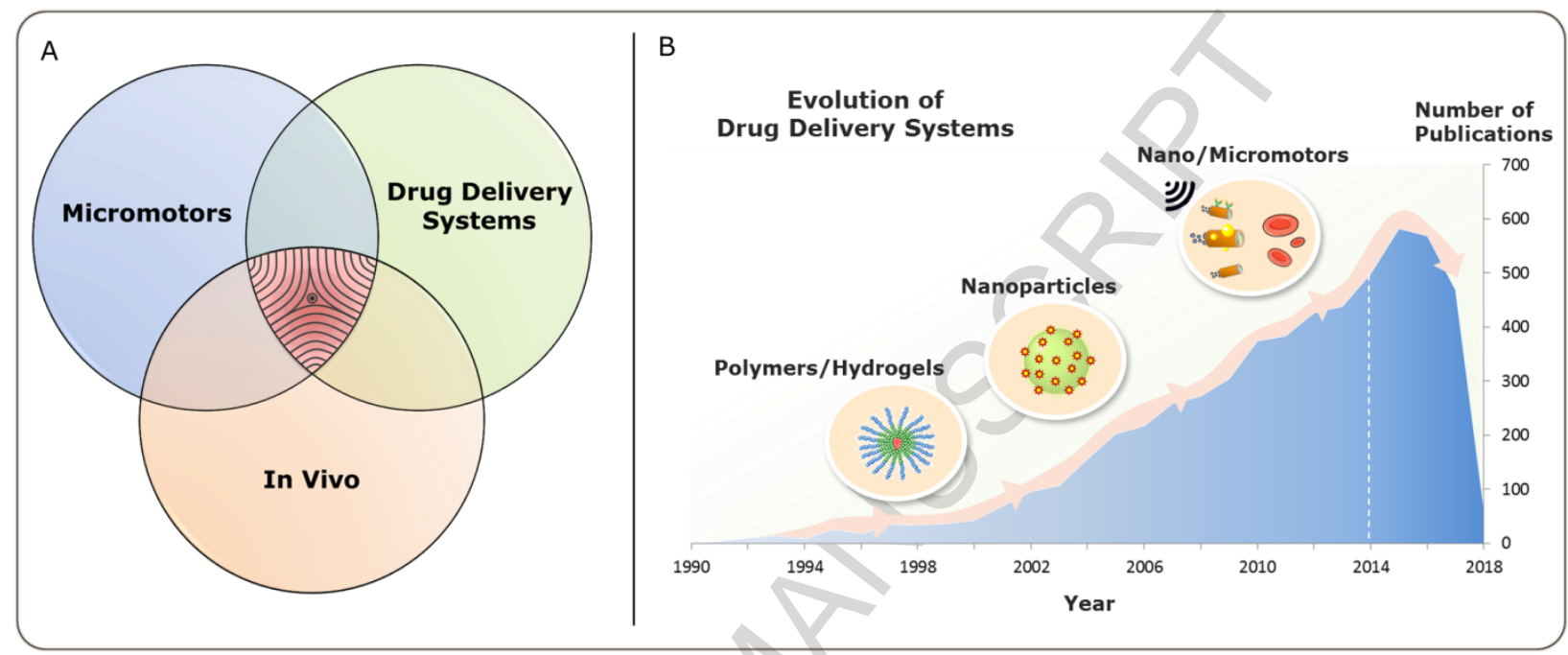

Figure 1. (A) Diagram depicting the main focus of this review as in vivo applications of micromotor for drug delivery. (B) Timeline showing the evolution of the number of publications per year on exogenoustriggered drug delivery systems [PubMed search: (ultrasound OR magnetism OR light OR NIR) AND "drug delivery systems"]

\section{Factors Governing Design-Application Relationship:}

1) Active vs Passive Targeting: How can externally actuated DDS make a difference?

Passive targeting refers to the transport of a drug via blood plasma to the site of interest. Its success is directly dependent on blood circulation parameters (like circulation time and activity of macrophages among others). Therefore, all oral and systemic DDS are essentially passive targeting systems, as the drug is carried to the diseased tissue via blood plasma. On the other hand, Active targeting refers to approaches that include target-specific moieties to enhance drug accumulation in the target tissue via blood 
circulation (i.e. Paul Ehrlich idea of a "magic bullet").[13] However, this active targeting should not be confused with site-directed targeting achieved via autonomous propulsion or external actuation.[14] For instance, inflammatory tissues and solid tumors both exhibit increased drug retention owing to their leaky vasculature system. This phenomenon is known as 'Enhanced Permeability and Retention' (EPR effect) [15] which is more prominent in murine models than human beings.[16] Uptake of the drug in the solid tumour by the virtue of blood circulation, observed in EPR effect is 'passive targeting'. In a similar scenario, if we incorporate additional ligand groups like antibody, polysaccharide or peptides for active targeting of over-expressed receptors in the diseased tissue, this improved site-specificity is referred to as 'active targeting'. However, such a conventional 'active targeting' DDS is still dependent on the blood circulation and inherent flow gradient. This becomes a serious issue when we correlate blood flow rate $(>5 \mathrm{~L} / \mathrm{min})$, which is approximately $1.5-33 \mathrm{~cm} / \mathrm{s}$ (at capillaries and venules)[17], with the total length of the human blood vessels i.e. 100,000 km[18] (diameter of planet Earth is $12,742 \mathrm{~km}$ ). Consequently, following scenario unfolds: (i) a nanomedicine/drug carrier circulating the blood stream faces, an arduously long journey at extremely high speeds (>several $\mathrm{cm} / \mathrm{s}$ ); (ii) It bypasses a tumour (at most, a few centimeters in size) in sub seconds; (iii) ligand-receptor interaction (even if it exists at endothelial surface) must happen in this extremely narrow 'window of opportunity' without being accumulated in the normal tissues (where such receptors are also expressed). Clearly, cancer nanomedicine has come under strong scrutiny and requires a radically new approach which can: (a) influence the motion/direction of a DDS, to direct it at the target site, (b) without being entirely dependent on the local fluid gradients (like blood flow), (c) followed by site-specific drug release. Such a DDS can be termed as a nano/micromotor (depending upon its size scale) with its inherent ability to propel/navigate against the flow, facilitating local tissue maneuvering, can provide new 
insight for drug delivery against solid tumors. A systematic assessment of cancer nanomedicine has revealed several shortcomings for nanoparticle mediated drug delivery in solid tumors[19][20] as: (i) amount of drug delivered to the tumor is less than $5 \%$ of the injected dose $(0.7 \%$ by recent estimates) [21]. While, one may argue that nanoparticle dosage (inferred from injected dosage) is not a true representation of pharmacokinetic activity [22], there exists little information to corroborate any further. [23]; (ii) design of nanovector may not be as important as thought since it's uptake is still dependent on the blood circulation; (iii) ligand-receptor interactions (i.e. "homing feature") come into picture only after drug carrier extravasate into tumour; (iv) "over expressed" surface receptors used as disease targets are often also expressed on healthy cells, thereby compromising the "homing/silver bullet" feature. Therefore, by recognizing the scope for improvement (figure 1B), efforts have been focused on physically actuated nano/micro DDSs to provide higher degree of control and improved drug efficacy.[24][25] This also becomes crucially important depending upon the chemical nature of the drug. For instance, drugs with low solubility in aqueous environment have limited uptake in diseased tissues (which includes most of the chemotherapeutics).

In this regard, micromotors have shown significant progress ranging from chemotherapeutic delivery (medibots)[26] [27], nucleic acid delivery[28], performing microbiopsies [29] and even assisted fertilization[30], all under in vitro setting. Being a 'motor' (i.e. characteristic motion properties) may offer a significant advantage as they can be externally actuated (along with activated drug release) or autonomously propelled for local drug delivery. Therefore, these nano/micromotors, in true terms, can help bridge the gap in chemotherapeutic delivery by having directed motion independent or less dependent on local fluid gradients like blood circulation in the near future. 


\section{Micromotors: Mode of guidance/actuation vs. Mode of release/activation}

Conventionally speaking, the term 'actuate' has been reserved for mechanical processes and is often used to describe motion properties. The term 'activate' on the other hand has been used to elucidate chemical conversion of a compound (reactant) or its state. For externally-triggered DDSs, the trigger or control mechanism should be applied locally and non-invasively. Therefore, it is important to briefly discuss these parameters with respect to their clinical significance towards micromotors development. These DDSs are able to respond to an external or exogenous trigger (ultrasound, magnetism, light, heat, electricity) due to the incorporation of specific stimuli-responsive materials. For example, iron oxide particles will respond to magnetic fields or UV/Vis light can execute photoreactions.[31] While one can recognize their relevance towards local drug delivery, it is equally important to understand how the choice of external triggers affects the design of the DDS, and its associated drug delivery parameters. In this section, we have briefly discussed chemical and physical triggers/control mechanisms present in these micromotors followed by another section on their clinical relevance.

Micromotors for drug delivery are mostly fabricated via a multi-stage process such that the drug is loaded into a hollow microcontainer, drop-casted or adsorbed onto a surface. It consists of distinct assemblies such as drug, support layer, polymeric chassis, stimuli-responsive layer/particles among others) and is not part of the conventional 'liquefied drug polymer'[32] production line. Therefore, if the dissolution process is drug-controlled, the overall bioavailability is largely governed by the chemical properties of the drug itself (as noted in case of low-water solubility like most chemotherapeutics, BCS II \& III). To this end, micromotor inducing micromixing effects are commonly observed in stationary/less turbulent fluid environment.[33][34][35] Clearly, such micromixing effects might be less prominent under physiological conditions like blood circulation (owing to high intrinsic flow gradient) but more valuable elsewhere (like GI tract), as discussed later. Nonetheless, externally actuated 
micromotors can provide localized accumulation which can be beneficial against chemotherapeutics delivery in solid tumour treatment.

Exogenous stimuli under clinical setting includes ultrasound, magnetic fields and light. The reason being that for a successful therapeutic delivery/effect, the radiation beam should be strong enough to reach deep into tissues without harming them and at the same time, interact locally with the DDS for actuation/drug release. From a biomedical perspective, only three windows of a complete spectrum facilitate deep-tissue penetration and absorption: $\mathrm{x}$-ray, radio frequency and acoustic radiation.[36][37] Since, the ionizing nature of X-ray poses significant health hazards, it is not considered as an ideal candidate for external stimuli.[38] Likewise, radio frequency waves cannot be focused on smaller tissues/regions owing to their large wavelength of 1 meter or above. This leaves us with electromagnetic and ultrasound (US) waves which can be focused into a focal point using principles of wave interference.[39] By accessing the progress made in the area of exogenous trigger release for drug delivery in vivo, and drawing parallels to micromotor technology, we hope to provide a benchmark as well as a combinatorial approach to open host of new opportunities in the near future (see Figure 2). 


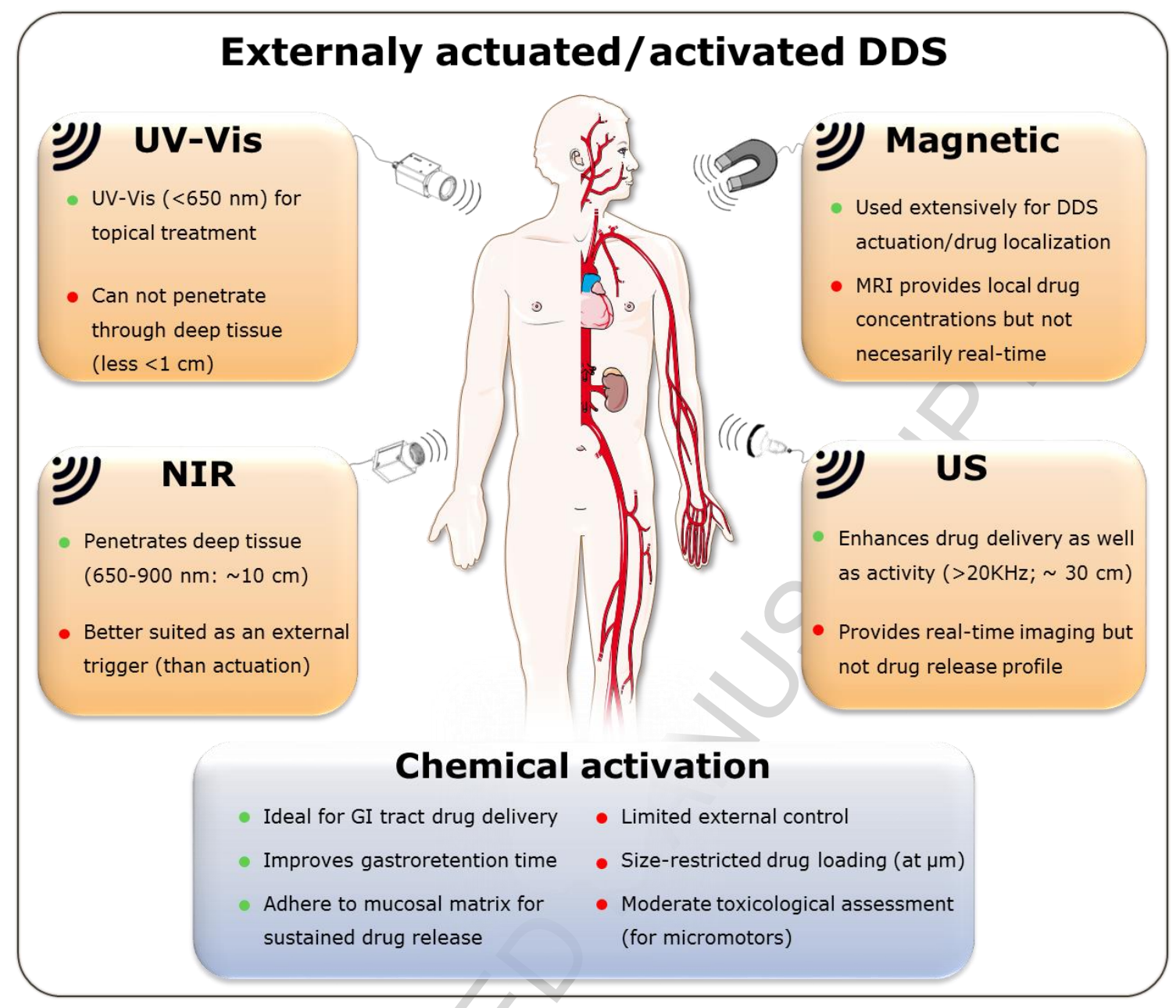

Figure 2: Schematic summary of external triggers used to actuate/activate drug delivery systems.

At this stage, it is important to understand that there are three components in any active micromotor namely: (i) mode of propulsion; (ii) mode of guidance; (iii) mode of release/activation. All externally actuated DDSs either incorporate elements for all the above or a combination thereof (refer to Table 1). Better understanding of these parameters, where each has a distinct advantage over the other (see Figure 2) depending upon the route/mode of application, is critical for improving drug delivery efficacy. 


\begin{tabular}{|c|c|c|c|c|c|}
\hline $\begin{array}{l}\text { Carrier and active } \\
\text { material }\end{array}$ & $\begin{array}{l}\text { Proposed } \\
\text { action/delivery }\end{array}$ & $\begin{array}{l}\text { In Vivo } \\
\text { animal } \\
\text { model }\end{array}$ & $\begin{array}{l}\text { Mode of } \\
\text { propulsion/guidance }\end{array}$ & $\begin{array}{l}\text { Mode of } \\
\text { release/activation }\end{array}$ & Ref. \\
\hline $\begin{array}{l}\text { Janus microparticles } \\
\text { (Au-SPIONs; } 3 \mu \mathrm{m})\end{array}$ & Tissue welding & $\begin{array}{l}\text { BALB/C } \\
\text { mice model }\end{array}$ & Magnetically guided & $\begin{array}{l}\text { Photothermal } \\
\text { activation }\end{array}$ & [40] \\
\hline $\begin{array}{l}\text { Hollow Ppy } \\
\text { microspheres }(2-3 \\
\mu \mathrm{m})\end{array}$ & $\begin{array}{l}\text { Imaging with trigger } \\
\text { release }\end{array}$ & $\begin{array}{l}\text { U87-MG } \\
\text { tumor } \\
\text { mouse } \\
\text { model }\end{array}$ & $\begin{array}{l}\text { Blood circulation } \\
\text { (passive targeting) }\end{array}$ & US-NIR & [41] \\
\hline $\begin{array}{l}\text { Fluorescence labelled } \\
\text { dextran particles }\end{array}$ & Gl tract delivery & $\begin{array}{l}\text { Yorkshire } \\
\text { pigs (ex } \\
\text { vivo); } \\
\text { C57BL/6 } \\
\text { mice (in } \\
\text { vivo) }\end{array}$ & US propelled & $\begin{array}{l}\text { Mucosal layer } \\
\text { adhesion }\end{array}$ & {$[42]$} \\
\hline $\begin{array}{l}\text { Octafluoropropane } \\
\text { trapped magnetic } \\
\text { microspheres (3-4 } \\
\mu \mathrm{m})\end{array}$ & $\begin{array}{l}\text { Pulmonary tract; } \\
\text { Real-time imaging } \\
\text { and drug delivery } \\
\text { (Cy5.5) }\end{array}$ & $\begin{array}{l}\text { Murine LL/2 } \\
\text { Lewis lung } \\
\text { carcinoma in } \\
\text { SCID mice }\end{array}$ & & US activation & [43] \\
\hline $\begin{array}{l}\text { PLGA microparticles } \\
(10 \mu \mathrm{m}) \text { with SPIONs } \\
\text { (magnetic } \\
\text { nanoparticles) }\end{array}$ & $\begin{array}{l}\text { Inflamation in } \\
\text { joints, } \\
\text { (Dexamethasone } \\
\text { acetate) }\end{array}$ & $\begin{array}{l}\mathrm{C} 57 \mathrm{Bl} / 6 \\
\text { mice }\end{array}$ & Magnetically guided & $\begin{array}{l}\text { Diffusion (via local } \\
\text { delivery) }\end{array}$ & [44] \\
\hline $\begin{array}{l}\text { Magnetic } \\
\text { microhelices }(20 \mu \mathrm{m})\end{array}$ & $\begin{array}{l}\text { Local delivery in } \\
\text { intra-peritoneal } \\
\text { cavity }\end{array}$ & $\begin{array}{l}\mathrm{BALB} / \mathrm{C} \\
\text { mice }\end{array}$ & Magnetic actuation & $\begin{array}{l}\text { NIR fluorophore } \\
\text { mediated imaging }\end{array}$ & [45] \\
\hline $\begin{array}{l}\text { PLGA-FeCo } \\
\text { microparticles }(50 \\
\mu \mathrm{m})\end{array}$ & $\begin{array}{l}\text { Anti-tumour drug } \\
\text { delivery, } \\
\text { Doxorubicin (DOX) }\end{array}$ & $\begin{array}{l}\text { New } \\
\text { Zealand } \\
\text { rabbits }\end{array}$ & Magnetically guided & $\begin{array}{l}\text { Diffusion (via local } \\
\text { delivery) }\end{array}$ & [46] \\
\hline $\begin{array}{l}\text { PEDOT/Zn tubular } \\
\text { micromotors }(20 \times 5 \\
\mu \mathrm{m})\end{array}$ & $\begin{array}{l}\text { In vivo propulsion } \\
\text { in stomach }\end{array}$ & ICR mice & $\begin{array}{l}\text { Chemical propulsion } \\
\text { (Gas evolution reaction) }\end{array}$ & $\mathrm{n} / \mathrm{a}$ & [47] \\
\hline $\begin{array}{l}\text { Mg based Janus } \\
\text { micromotors ( } 20 \text { - } 30 \\
\mu \mathrm{m}) ; \text { Eudragit L100 } \\
\text { coating }\end{array}$ & $\begin{array}{l}\text { In vivo propulsion } \\
\text { in stomach }\end{array}$ & ICR mice & $\begin{array}{l}\text { Chemical propulsion } \\
\text { (Gas evolution reaction) }\end{array}$ & $\mathrm{n} / \mathrm{a}$ & [48] \\
\hline $\begin{array}{l}\text { Mg-loaded } \\
\text { PEDOT/Au } \\
\text { microtubes (20 x } 5 \\
\mu \mathrm{m}) ; \text { Eudragit L100 } \\
\text { coated }\end{array}$ & $\begin{array}{l}\text { In vivo propulsion } \\
\text { through Gl tract }\end{array}$ & ICR mice & $\begin{array}{l}\text { Chemical propulsion } \\
\text { (Gas evolution reaction) }\end{array}$ & $\mathrm{n} / \mathrm{a}$ & [49] \\
\hline $\begin{array}{l}\text { Mg-microspheres (20- } \\
30 \mu \mathrm{m}) ; \text { Chitosan } \\
\text { coated }\end{array}$ & $\begin{array}{l}\text { Drug-PLGA matrix } \\
\text { (clarithromycin) }\end{array}$ & $\begin{array}{l}\text { C57BL/6 } \\
\text { mice }\end{array}$ & $\begin{array}{l}\text { Chemical propulsion } \\
\text { (Gas evolution reaction) }\end{array}$ & $\begin{array}{l}\text { Diffusion (via oral } \\
\text { delivery) }\end{array}$ & [50] \\
\hline
\end{tabular}

Table 1. Synthetic micro-DDS with various physical and chemical actuation/activation schemes.

\subsection{Exogenous control: Effects of light - NIR under in vivo conditions}


One of the fundamental requirements of a drug carrier is its ability to release drugs 'on demand' (to reduce toxicity elsewhere) and enhance efficacy by controlling time and duration of exposure. This is where photoactivation has found extensive usage in vivo.[51][52] These photo-triggered DDSs are externally activated by light/NIR, which causes drug release at the desired site and with a controlled rate, depending on the type of matrix used. Unlike US or magnetic fields, light-NIR triggers are mostly employed for controlled drug release rather than actuation in vivo. However, it should be noted that photoactivation has been demonstrated towards propulsion/docking of micromotors via a photo-catalytic reaction.[53][54] Limited in vivo studies can be attributed to the fact that UV and visible light $(<650 \mathrm{~nm})$ cannot penetrate deep tissue as (i) radiation below $650 \mathrm{~nm}$ cannot penetrate deeper than $1 \mathrm{~cm}$ into tissue due to high scattering; (ii) absorption by hemoglobin, oxy-hemoglobin, and water present in the tissue. Nonetheless, they have found clinical relevance towards topical drug delivery applications. In this regard, Near-infrared (NIR) mediated nano/microsystems garnered special attention as they can be focused onto a small specific area and penetrate deeply into the tissue with insignificant damage. NIR light of 650 - $900 \mathrm{~nm}$ (water absorbs wavelengths longer than $900 \mathrm{~nm}$ ) can penetrate up to $10 \mathrm{~cm}$ into living tissue with minimal tissue damage at the site of application.[55] Therefore, NIR-responsive microcarriers [56] with local payload release has provided significant advances in drug delivery applications (including photodynamic therapy (PDT), photothermic therapy (PTT), laser mediated tissue sealing). Readers can find a detailed review on possible photochemical mechanisms for drug delivery applications elsewhere.[31]

As for NIR-triggered micromotors in vivo, He et al. demonstrated Janus micromotor particles (3 $\mu \mathrm{m})$ facilitating photothermal tissue welding guided by magnetic/thermal influences in mouse model (Figure 3A).[40] The particle composition comprised of sputtered Au on one side and polyelectrolyte multilayers-SPIONs on the other side of the Si microparticles. The system exploits collagen denaturation $\left(50-70^{\circ} \mathrm{C}\right)$ followed by tissue softening and melting, whereby, a 
temperature decrease allows for condensation and a hard wound closure. Presence of Au particles in such a system has been well recorded for enhancing photothermal effects.[57][58] While laser tissue welding is a well-studied phenomenon[59], the authors claimed that the ability to magnetically guide the "dyes" in a wound facilitated sealing of actively bleeding wounds which in normal cases would flush the passive dye and nanoparticles out. Study performed in a mouse model demonstrated comparable results between motors, nanoparticle gluing and medical suturing (healing completed $\sim 9$ days) as show in figure 3A. Additionally, mechanical suturing introduced additional injuries and tissue deformation, which was avoided in case of laser tissue welding (although, thermal damage was observed for the latter). Also, animal tissue study performed ex vivo (beef liver) suggested that liver's mechanical properties can be restored with laser tissue welding and may provide an alternative for hemostatic treatment for targets with limited suturing potential (like liver and lungs). 

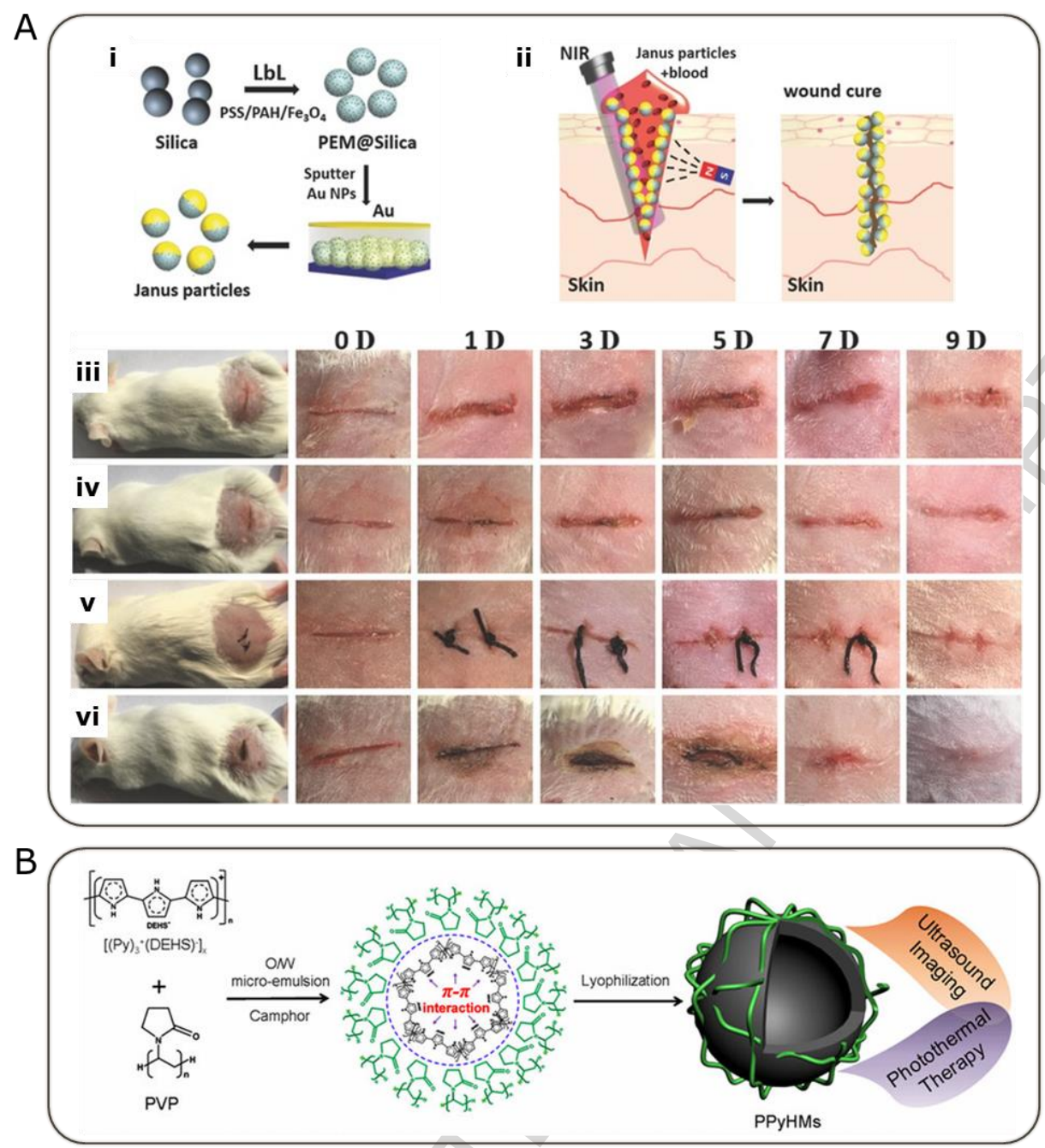

Figure 3: Exogenous control: Effects of light - NIR under in vivo conditions (3A) Guidable Thermophoretic Janus Micromotors Containing Gold Nanocolorifiers for Infrared Laser Assisted Tissue Welding. (i) Production of Janus composite particles by LbL self-assembly of PEM and magnetite nanoparticles followed by sputter coating with gold and resuspension in water. (ii) Laser tissue welding with magnetic assistance, due to magnetite particles being homogeneously distributed in the particles the particle orientation is random during welding. Examples of (iii) control sample (no treatment), (iv) laser tissue welding, (v) medical suturing, (vi) nanoparticle glue. Only the non-treated wound heals worse than the treated wounds. Laser tissue welding based on autonomous movable dyes heals comparable to medical suturing or nanoparticle gluing. (3B) Polypyrrole Hollow Microspheres as Echogenic Photothermal Agent for Ultrasound Imaging Guided Tumor Ablation. Schematic illustration of the formation of echogenic PPyHMs for combined US imaging and PTT via a facile O/W microemulsion method. Image reproduced with permission from $[40][41]$

While plethora of studies exist discussing light-activation of nano/microscale DDSs, we have taken efforts to discuss some interesting microscale systems that can provide valuable insight 
for micromotor technology. In this regard, Zha et al. reported hollow polylyyrrole microspheres $(2-3 \mu \mathrm{m})$ for dual-action ultrasound imaging with phototrigger drug release in vivo. [41] Coupled with ultrasound mediated imaging, a NIR laser ablated the tumor completely within two weeks as observed in a U87-MG tumor mouse model. An easy yet intelligent design scheme incorporating oil-in-water emulsion method (Figure 3B) has been applied to make these NIR absorbing hollow microspheres from polypyrrole. Obtained polypyrrole hollow microspheres (PPyHMs) can act as efficient theranostic agents not only to greatly enhance US imaging, but also to achieve excellent photohyperthermic effects (earlier demonstrated with incorporation of Au nanoparticless)[60]. What makes this study interesting for the micromotors community, is the fact that Polypyrrole (PPy) materials have already been tested for micromotor fabrication, including cargo delivery under in vitro setting. [61][62] Further, PPy offers both stability[63] and biocompatibility [64] towards designing such photoactive DDSs for in vivo applications.

\subsection{Exogenous control: Effects of Ultrasound (US) under in vivo conditions}

US (frequency above the audible range of humans; $>20 \mathrm{kHz}$ ) can be focused on very small areas due to its wavelength in the order of millimeters. It has been employed for both enhancing the delivery as well as the activity of drugs over the past two decades.[65][66] The enhancement in drug uptake by US relies on a phenomenon known as acoustic cavitation, typically seen as a cloud of bubbles forming in the vicinity of the ultrasonic source. [67] Cavitation is the formation of low-pressure voids (vacuum bubbles or cavities) in the liquid, which grow, briefly oscillate, and then asymmetrically implode with great intensity. The resulting microjets can physically propel drug/particles into tissue as well as reversibly permeabilize tissue to allow enhanced drug uptake. Therefore, we can say that US mediated cavitation appears to play two key-roles: (i) it propel/disrupt the structure of carrier vesicle (and releases the drug); (ii) makes cell membranes and capillaries more permeable to drug. 
While US has found significant clinical application towards imaging, lithotripsy and even transdermal drug delivery, its direct application with conventional systemic and local drug delivery has been rather limited. Nonetheless, US could also serve as an external trigger for drug delivery systems in vivo. A key-feature that makes US interesting as a clinically relevant platform for micromotor drug delivery is its dual-capacity for both imaging as well as actuation/drug release. This becomes important as imaging has been a key-challenge towards in vivo deployment of micromotors.[68] Further, recent research suggests that US can also be used for drug delivery applications in the Gl tract [69] (in addition to the skin [70]) thereby allowing the successful delivery of small molecules, biologics, and nucleic acids.[71][42] Schoellhammer et al. [42] demonstrated US-mediated targeted drug delivery in a mice model. As a proof-of-concept study, they delivered fluorescence-labelled dextran particles $(2 \mu \mathrm{m})$ into the colon of mice followed by local US exposure. It was observed that the dextrans could be delivered very fast, deep into the epithelial tissue (Figure 4A). This was also confirmed by SEM images as: (i) untreated tissue showed thick mucus layer without crypts; (ii) US-treated tissue clearly showed evenly distributed crypts suggesting that US dissipates the mucus layer for enhanced delivery and; (iii) US-mediated delivery demonstrated uniform distribution of microparticles with no clustering. Nonetheless, it should be mentioned that, as they observed removal of mucus layer, there could have been detrimental consequences for the underlying intestinal tissues.[72] This 'gap' can be well-covered by chemically-propelled micromotors (as discussed later), which tend to 'shoot and stick' at the mucosal lining in the stomach (mucoadhesion), thereby, opening novel options for deep-tissue drug delivery in the Gl tract. 

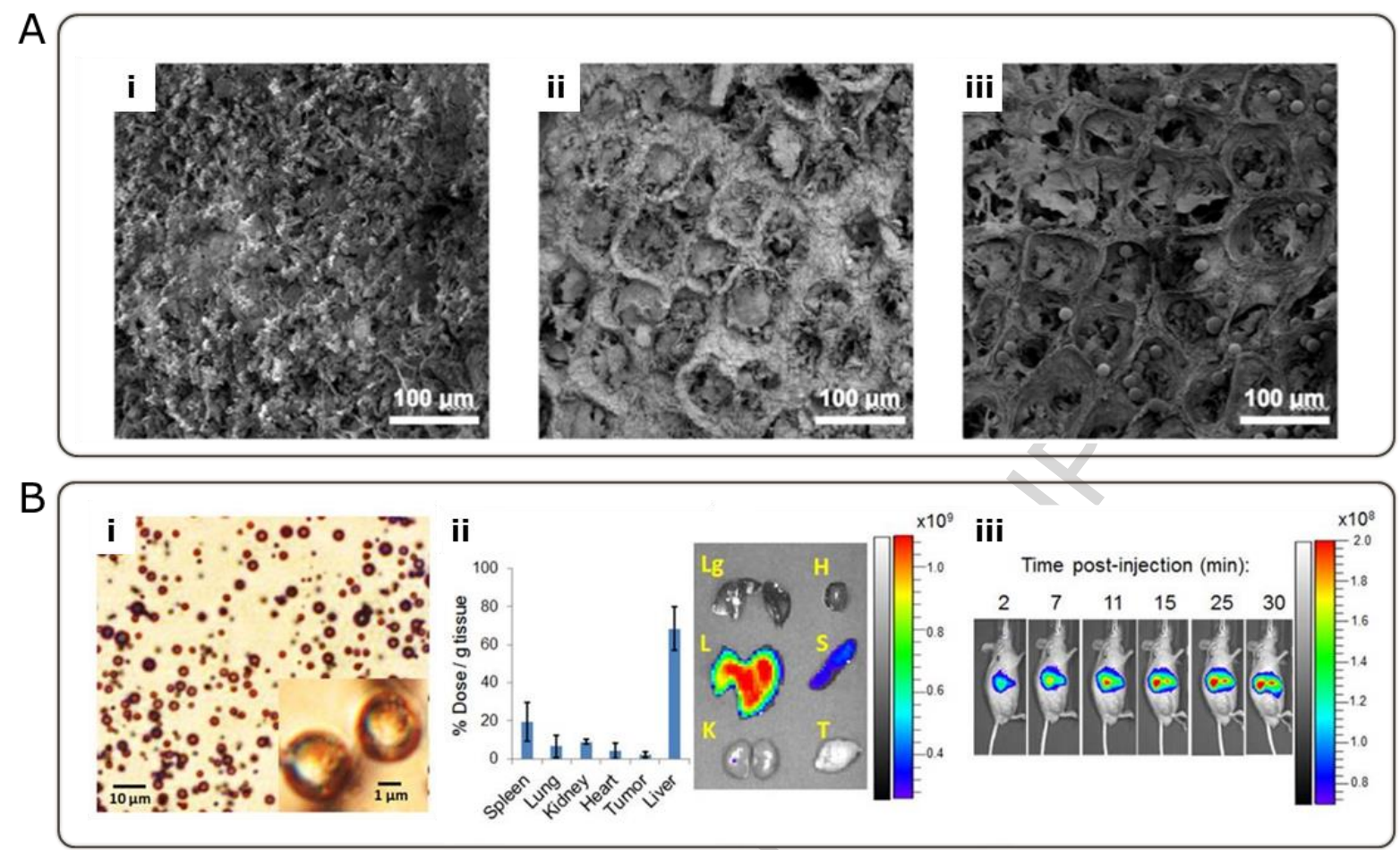

Figure 4: Exogenous control: Effects of Ultrasound (US) under in vivo conditions. (4A) Defining optimal permeant characteristics for ultrasound mediated gastrointestinal delivery. SEM micrographs of porcine colonic tissue not treated with ultrasound (i) and after treatment with ultrasound (ii). (iii) Porcine colonic tissue after simultaneous treatment with ultrasound and 15 $\mu \mathrm{m}$ diameter latex beads. (4B) Circulating Magnetic Microbubbles for Localized Real-Time Control of Drug Delivery by Ultrasonography-Guided Magnetic Targeting and Ultrasound. (i) Representative bright-field phase contrast micrographs of MagMB (Inset: high magnification (100x) phase-contrast micrograph of MagMB). (ii) Organ biodistribution of MagMB-Cy5.5 quantified ex vivo by fluorescence spectrophotometry $30 \mathrm{~min}$ post administration. Data represent mean $\pm S D, n=4$. Representative qualitative biodistribution profiles of MagMB-Cy5.5 analyzed by fluorescence imaging 30 min post-administration (Lg: lungs; L: liver; $\mathrm{K}$ : kidneys; $\mathrm{H}$ : heart; $\mathrm{S}$ : spleen; $\mathrm{T}$ : tumor). Color bar represents fluorescence radiant efficiency expressed in

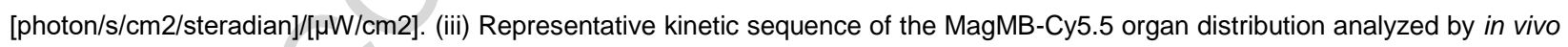
whole-body fluorescence imaging over a $30 \mathrm{~min}$ time interval post administration. The color bar represents fluorescence radiance expressed in [photon/s/cm2/steradian]. Image reproduced with permission from [42][43]

Another important area where US may find a slight edge over magnetic systems is the ability to be focussed in a smaller area. Magnetically controlled systems in vivo are highly dependent on magnetic field strength. Technically, it is difficult to build-up sufficient field strength focussing on a small area such that it is able to counteract linear blood flow rates in tissues $(>10 \mathrm{~cm} / \mathrm{s})$ and arteries $(0.05 \mathrm{~cm} / \mathrm{s})$. While one may argue that sufficiently strong magnets are available now 
(MRI operates at 1-3 T; or using rare earth magnets for localization), avoiding normal tissue clearance, is still a major challenge in drug delivery. Under clinical setting, it is important not only to achieve local drug delivery but also monitor real-time pharmacokinetics. For example, while US imaging allows rapid visualization using contrast agents, it does not provide much information about drug release profile and local action. However, Magnetic Resonance Imaging (MRI) can provide local drug concentrations with limilted real-time capabilities. Therefore, upon combining them together, one may achieve both local drug administration and pharmacokinetic assessment.

Recently, Langer et al. demonstrated this combinatorial approach by combining the features of both magnetic and US theranostic systems towards the fabrication of magnetic microbubbles (MagMB).[43] These MagMB are essentially hollow (gas-trapped) lipid microparticles (3-4 $\mu$ m; Figure 4B) that are responsive to both magnetic (owing to the presence of iron oxide nanoparticles) and acoustic modulation and visible to ultrasonography towards real-time control of drug delivery. As shown in figure $\mathbf{4 B}$, following intravenous injection in mice, MagMB exhibited a 17- 90 fold lower pulmonary entrapment (compared to previously reported magnetic microbubbles; circulation time > $10 \mathrm{~min}$ ) and could be accumulated in tumor vasculature (' $\mathrm{L}$ ' symbolizes lungs) by magnetic targeting, monitored by ultrasonography and collapsed by focused US on demand to activate drug deposition at the target. US guided burst delivery of microbubbles with genetic material can also be a dual action solution allowing both imaging and drug delivery.[73]

\subsection{Exogenous control: Effects of magnetism under in vivo conditions}

Early studies of magnetic guidance/drug localization can be traced back to a series of reports by Kato et al. towards selective cancer chemotherapy.[74] Starting from albumin-magnetic microbeads to ferromagnetic mitomycin microcapsules (about $300 \mu \mathrm{m}$ ), these DDS were 
magnetically localized in vivo at the site of a tumor. This suggests that the idea of overcoming systemic drug side-effects has been a key-driver for magnetically activated DDSs. This has been achieved by incorporating a layer/assembly of magnetically responsive nano/microparticles which respond to the magnetic field. Generally, Iron, Cobalt, Nickel, superparamagnetic Iron particles (SPIONs) among others are used for drug delivery applications.

However, one key-difference between such studies and current generation of micromotors is the fact that external fields are also used for active mobilization of the DDSs and not merely limited towards accumulation of DDS in a desired location (i.e. tissue localization). This can be understood by the fact that a magnetic object under a homogeneous magnetic field will not experience gradient forces. Therefore, the object cannot be moved (actuated), but still this method can be used to localize the object (DDS) at a specific site to prevent its random diffusion. On the contrary, in case of magnetically actuated DDSs, it is important that the dipole is not aligned with the direction of the applied magnetic field resulting in a torque (as in case of micromotors).[75] In either of the cases, this promises to improve the targeting efficiency of magnetic carriers as well as enhance the drug availability at the molecular site of action.

While it is known that magnetic localization of a therapeutic agent results in better effective dosage concentration, some studies have also demonstrated it to act as a bio-compatible sustained trigger over a long period of time. A study by Butoescu et al. demonstrated that magnetically retainable DDS $(1 \mu \mathrm{m}$ and $10 \mu \mathrm{m})$ may overcome current limitations of intraarticular corticosteroid injections in joints (i.e. drug-crystal induces arthritis and repeated injections in joint). They demonstrated slow release of dexamethasone, over a period of three months, by applying an external magnetic field to avoid problems of drug re-crystalization in joints.[76][44] 
Interestingly, there was no significant difference regarding presence or absence of a magnet near the joint (two weeks post-administration). This was speculated to be due to the action of macrophages, clearing out these magnetic microparticles, thereby, minimizing the influence of a magnet. However, over a longer period of observation (Figure 5A), histological images further confirmed that the microparticles are still present in the joint, three-months post-injection with no inflammatory response or damage to the synovial lining. This also indicates that such magnetic particles pose no significant health risk. Therefore, magnetically actuated micromotors may provide pharmacologically relevant solutions in the area of inflammatory diseases upon incorporation of different APIs/drugs.
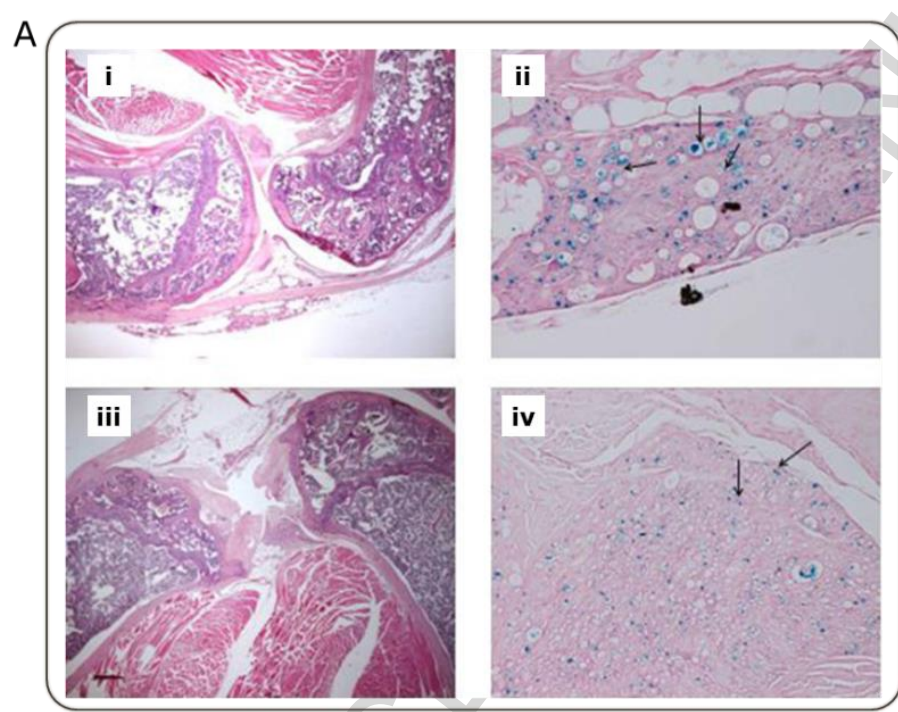
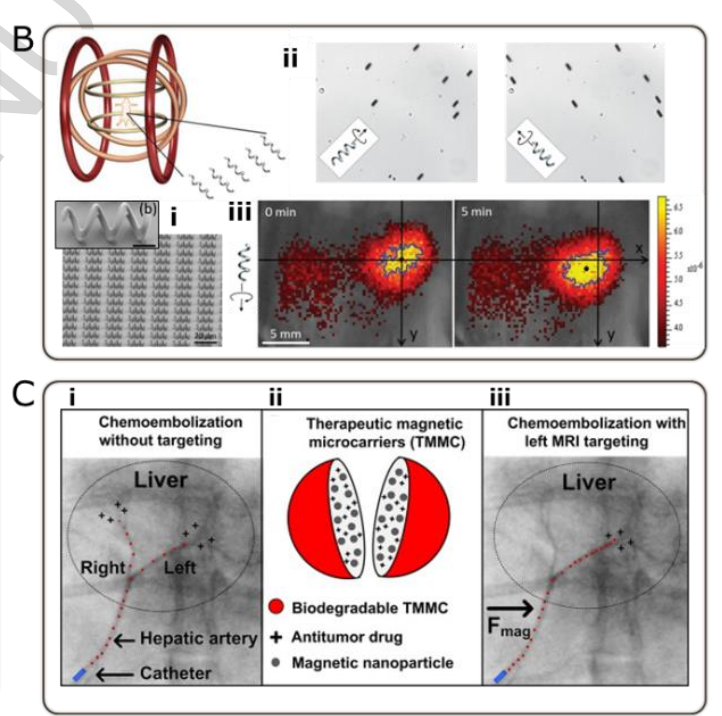

Figure 5: Exogenous control: Effects of magnetism under in vivo conditions. (5A) Magnetically retainable microparticles for drug delivery to the joint: efficacy studies in an antigen-induced arthritis model in mice. Histology of mouse knee joints 3 months after intra-articular injection of either $10 \mu \mathrm{m}$ ( $\mathrm{i}$ and ii) or $1 \mu \mathrm{m}$ (iii and iv) microparticles. Of note, even after 3 months, both types of microparticles are present in the tissue surrounding the joint cavity. Prussian blue (PB) staining provides evidence of iron within the microparticles; see arrows in (ii and iv). No major signs of inflammation are evident. Original magnifications: x20 (i and iii), x400 (ii) and x100 (iv). Stains: haematoxylin and eosin (i and iii) and PB (ii and iv). (5B) Controlled In Vivo Swimming of a Swarm of Bacteria-Like Microrobotic Flagella. (i) Image of a single or an array of $16 \mu \mathrm{m}$ artificial bacterial flagella (ABF) fabricated by Direct Laser Writing (DLW). (ii) Controlled swimming of f-ABF swarm in vitro under $9 \mathrm{mT}$ and $90 \mathrm{~Hz}$ on a polished Si wafer in distilled water tracked by optical microscopy. (iii) Swimming of a swarm of $f$-ABFs in the intra peritoneal cavity of a Balb-C mouse 
under $9 \mathrm{mT}$ and $90 \mathrm{~Hz}$ (total movement of the swarm center of mass: $1.3 \mathrm{~mm}$ ). The contour of the yellow cloud was determined using a homemade Matlab code and was used to determine the movement of the swarm of $f$-ABFs. (5C) Co-encapsulation of magnetic nanoparticles and doxorubicin into biodegradable microcarriers for deep tissue targeting by vascular MRI navigation. Representation of MRI targeting with TMMC for liver chemoembolization by fluoroscopy images of the rabbit hepatic artery with superposed images of the TMMC distribution without (i) and with (iii) the MRI targeting. On image (i), the microparticles are released from the catheter in the artery and distributed to both lobes. (ii) Schematic representation of a cut of the TMMC loaded with an antitumor drug and magnetic nanoparticles embedded into a biodegradable matrix. (iii) displays the MRI targeting of the left bifurcation using the magnetic force (Fmag) to preserve the right lobe from the chemoembolization. Image reproduced with permission from [44][45]. Figure 5C Reprinted from Biomaterials, 32, P. Pouponneau, J.C. Leroux, G. Soulez, L. Gaboury, S. Martel, Co-encapsulation of magnetic nanoparticles and doxorubicin into biodegradable microcarriers for deep tissue targeting by vascular MRI navigation, 3481-3486, Copyright (2011), with permission from Elsevier.

While, a few years ago, lack of better controls and imaging modalities would have hampered the growth of such magnetic microswimmers in vivo, a recent study by Nelson et al. offers a breakthrough solution for the same.[45] They demonstrated that magnetically-actuated synthetic microswimmers loaded with NIR-fluorophores could navigate in the peritoneal cavity of mice providing real-time tracking via live fluorescent imaging (figure 5B). These microhelices respond to a magnetic field produced by AC currents, and in turn, actuate micromotor motion by modulating direction and magnitude of the resulting magnetic field (DC magnetic field is constant).

This is a significant step forward facilitating site-directed 'motion \& tracking'. In this regard, Magnetic resonance navigation (MRN) also provides a significant opportunity for nano/micromotor development. In another study, Martel et al. demonstrated PLGAmicroparticles $(50 \mu \mathrm{m})$ loaded with the antitumor drug doxorubicin and iron-cobalt nanoparticles for optimal steering properties (figure 5C) [46]. MRN was demonstrated for tumor targeting of microparticles and it was furthermore confirmed that the systemic concentration of doxorubicin was minimized due to the localized drug release in the target area. It was also observed that these microparticles could be steered in the hepatic artery, with a depth of $4 \mathrm{~cm}$ below the skin. This clearly highlights the potential micromotors possess in terms of clinically relevant solutions. 
The above mentioned drug localization phenomenon was further confirmed by Price et al. towards targeted delivery in lungs for treating lung cancer. [77]. They demonstrated magnetic microparticles $(50 \mu \mathrm{m})$ encapsulating doxorubicin used for site-specific drug localization on one side of the lung via an external magnet (showing 10-fold increase of particle deposition).

\section{Chemical activation: Utilizing body fluids as a fuel for propulsion in vivo}

Chemically-propelled micromotors are another class of actively propelling microscale DDS that have been widely investigated. These effervescent autonomous microswimmers can be divided into two categories: (i) Catalytic micromotors and (ii) Chemical micromotors (Non-catalytic). As the name suggests, catalytic micromotors are specific geometries of heterogeneous catalysts, promoting high turnover numbers, under the aqueous reaction environment for bubble propulsion (via a gas evolution reaction).[78] For example, hydrogen $\left(\mathrm{H}_{2}\right)$ evolution reaction in the presence of $\mathrm{Pt} / \mathrm{Ag}$ as catalyst with hydrogen peroxide (which has been a key driver for the early reports of such catalytic micromotors).[79] However, utilizing hydrogen peroxide as a fuel in living organisms is not the most viable idea owing to its potential toxic side-effects. Due to this, chemical or non-catalytic micromotors are of considerable interest. Mou et al. reported 'comparatively biocompatible' Mg-Pt micromotors based upon passivation of $\mathrm{Mg}(\mathrm{OH})_{2}$ in $\mathrm{NaHCO}_{3}$ and the resulting reaction between $\mathrm{Mg}$ and $\mathrm{H}_{2} \mathrm{O}$ generated $\mathrm{H}_{2}$ bubble for propulsion. As the active agent (propellant) rapidly got consumed in the chemical reaction (in this case, $\mathrm{Mg}$ ), the life span was reported to be 80 seconds only. Nonetheless, these chemically-activated micromotors exhibiting gas evolution reaction, and later turned out to be the ones which were introduced in vivo. As it stands within the framework of chemistry, a catalyst, by definition, should not get consumed in a chemical reaction. Although catalytic, non-catalytic or chemical micromotors have been used indistinguishably in the literature.

Conceptually, these chemically-propelled micromotors are very similar to effervescent floatingtype drug delivery systems (FDDS),[80] which have found significant usage in the Gl tract drug 
delivery for over three decades. Based upon their mode of propulsion, these FDDS can be regarded as effervescent FDDS (gas generation) or non-effervescent FDDS (buoyant preparations include hollow microspheres or 'microballoons' among others)[81]. In fact, chemically-activated micromotors have much in common with these effervescent FDDS where active components like sodium bicarbonate, citric acid or tartaric acid (and acid-base mixtures) have been extensively employed in Gl formulations including antacids, treatment against microbial diseases and improved drug bioavailability. [82][83][84][85] For instance, Özdemir et al. demonstrated an enhanced bioavailability of furosemide drug via gas evolution reaction involving sodium bicarbonate and citric acid. [86] In terms of pharmacological significance, three main advantages can be cited for such a floating type or chemically propelled system in Gl tract [87]: (i) avoid periodic emptying cycles in stomach (myoelectric cycles); (ii) increased gastroretention time (GRT) ; (iii) mucoadhesion properties for sustained drug release.[88][89]

Fate of a drug along the GI tract depends on following parameters: (a) permeability of GI mucosa and transit rate in GI tract; (b) variable gastric emptying of pharmaceuticals, which is also dependent on the dosage form (including fast/fed state); (c) highly acidic stomach environment together with aggressive enzyme cocktails that can degrade API/drug. Likewise, for an effervescent FDDS, the main objective is to remain buoyant via a gas-evolution reaction (or entrapment) to avoid being cleared out from the stomach. At the same time, they protect the drug from harsh Gl environment, achieve mucosal layer adhesion via polymer swelling and ultimately resulting in sustained release of the drug. In this context, micromotors may be able to achieve the same, albeit faster, due to the intrinsic autonomous propulsion/motion control. With an aim of promoting open scientific discussions, part of us would like to present the first prototype concept (unpublished) of an 'oral - micromotor incorporated DDS' as shown in figure 6. Biocompatible polymeric microcontainers can be bulk-produced and loaded with both - drug and a suitable propellant $\left(\mathrm{CaCO}_{3}\right.$ in our case). Gastroretention time (GRT) can be further 
enhanced by covering these microcontainers with a polymeric cap to avoid drug degradation. Finally, resulting drug-propellant microcontainers, can be easily filled into a capsule for oral administration, much like a normal capsule with drug granules inside. Such a dynamic oral DDS safeguards the drug in harsh GI environment and facilitates characteristic micromotor propulsion (upon dissolution of outer capsule matrix via a polymer swelling process). Our initial studies (Figure 6) have strongly suggested that these drug loaded microcontainers offer a viable solution for an age-old challenge of bioavailability in orally administered drugs, which needs to be further investigated by the DDS community. In fact, we have dedicated an entire section towards discussion of such micromotors in Gl tract owing to their growing significance under in vivo setting.

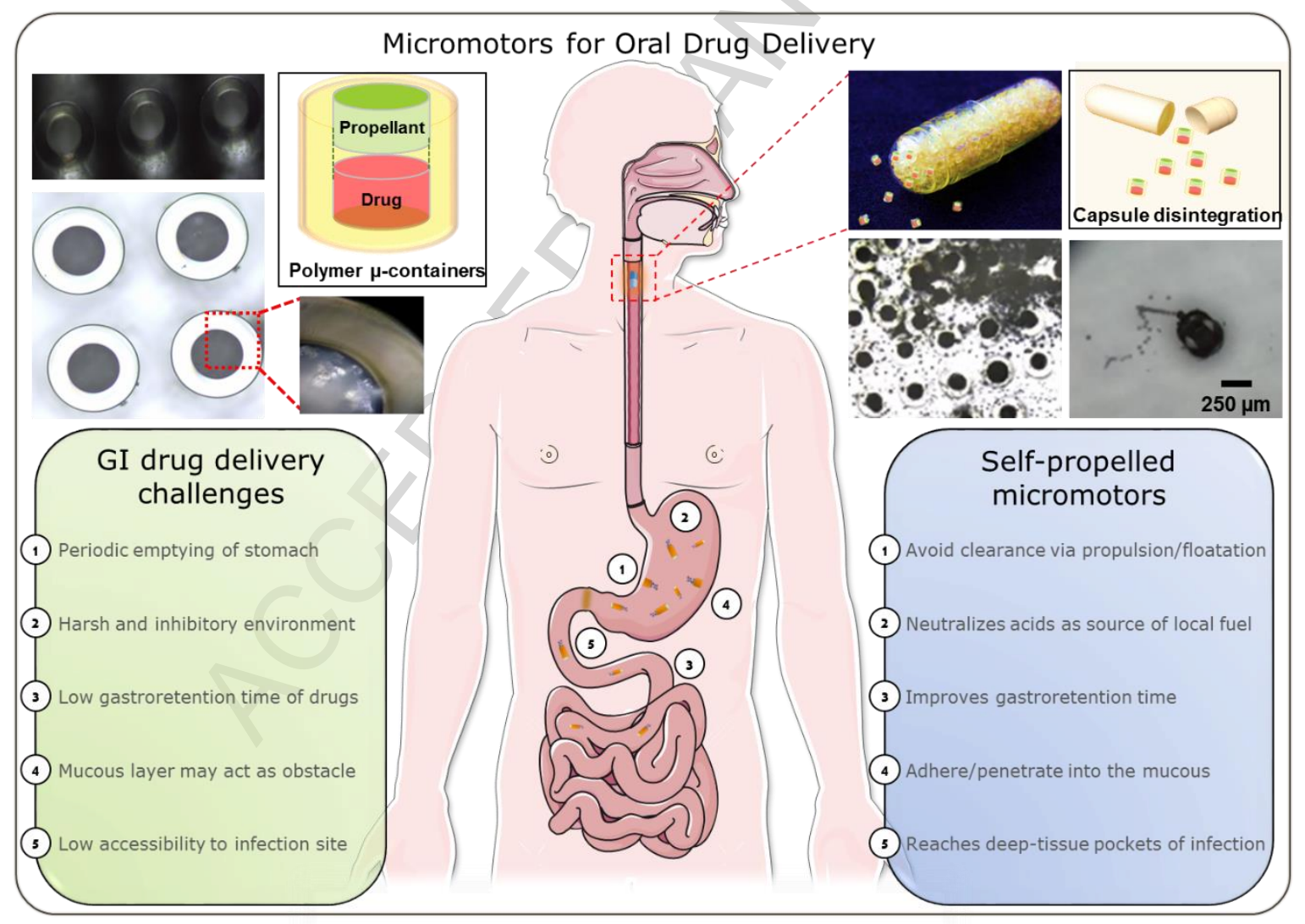

Figure 6: Oral DDS depicting a capsule filed with drug loaded micromotors and comparative assessment of GI tract drug delivery between conventional vs dynamic DDS. 


\section{Micromotors in GI tract: Exploring clinical relevance and future opportunities}

One of the key differences between autonomously propelled micromotors and effervescent FDDS is its size-scale. As the name suggests, micromotors are in the range of micrometers while a normal FDDS formulation is in the scale of millimeters. However, if one truly talks about pharmacological significance or effective dosage, it is imperative that significantly higher drug loading will be required for any Gl tract drug delivery application (gastroretentive dosage). [90] This also requires pharmacological assessment (which is not limited to single particle motion properties). For example, antibiotic administration against bacterial infections (like H. Pylori) encounters several challenges[91] including (a) antibiotics are unstable in the low pH of gastric acid; (b) the concentration of the drug in the deep gastric mucus where the bacterium lives is too low; and (c) the amount of time that the antibiotic resides in the stomach is too short. Therefore, micromotors for Gl tract drug delivery needs to target upon the above parameters to move beyond a proof of concept study.

Gao et al. demonstrated efficient micromotors propulsion under in vivo conditions (Figure 7A).[47] PEDOT/Zn tubular micromotors utilized gastric acid $(\mathrm{HCl})$ for propulsion $\left(\mathrm{H}_{2}\right.$ via oxidation of zinc with acid) in mouse stomach. This autonomous propulsion allowed micromotors to penetrate into the soft mucosal layer (without inducing any destructive effect on the gastric epithelial cells), and increase their retention in the stomach tissue. This was confirmed by analyzing the stomach tissue post-administration (oral, $2 \mathrm{~h}$ ) as compared to the control (Pt non-motile). 

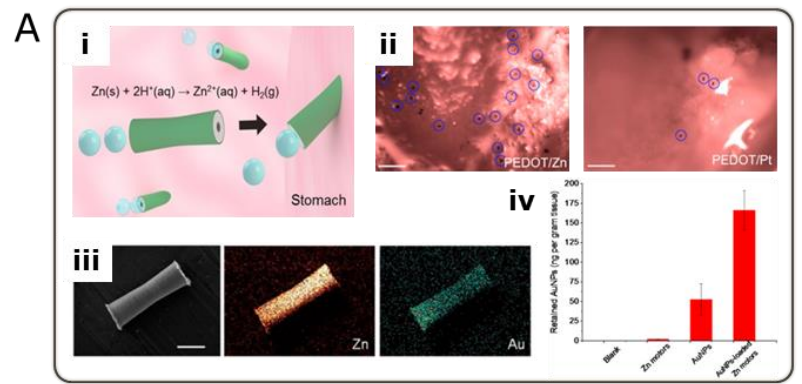

C

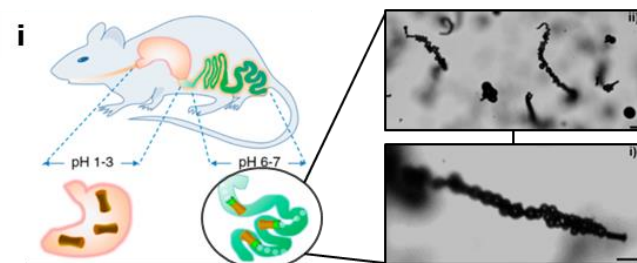

ii

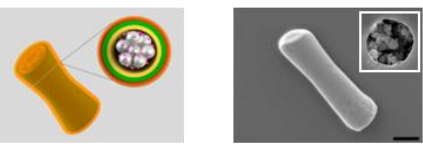

iii
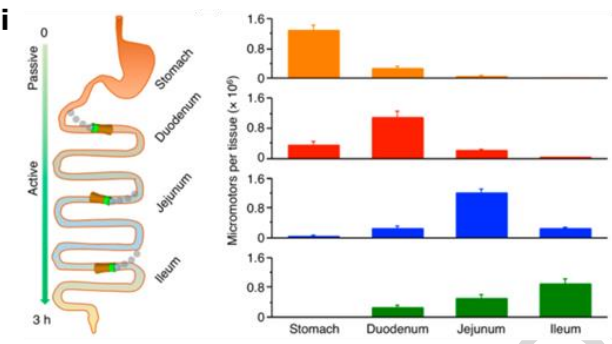

iv

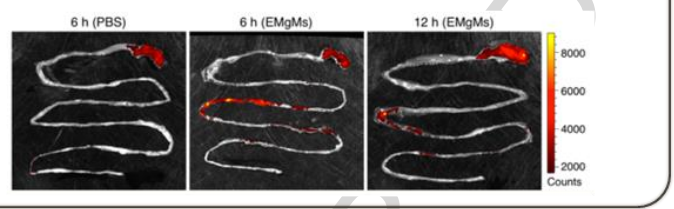

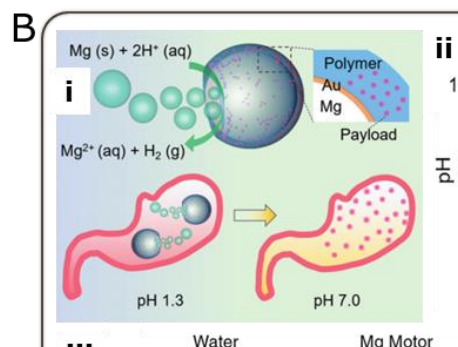
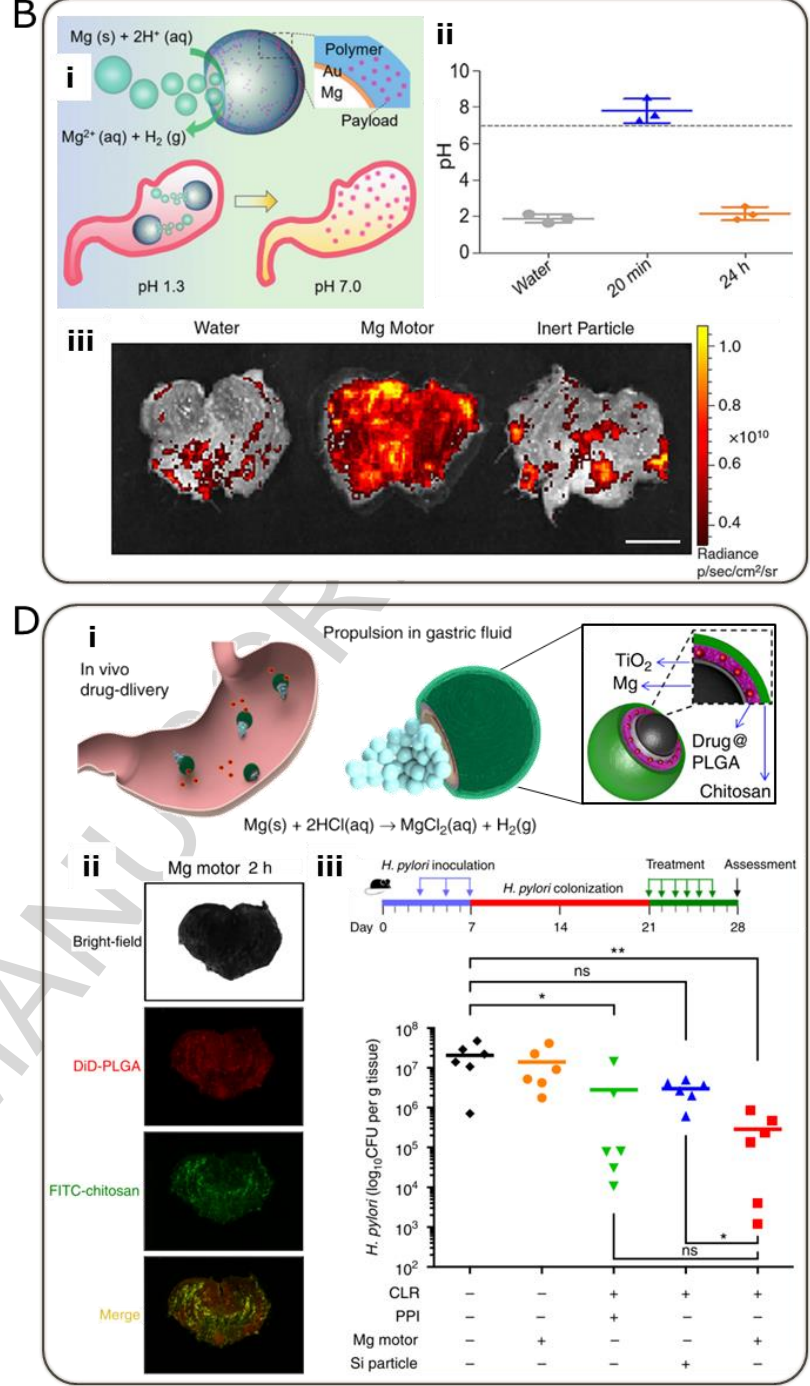

Figure 7: Examples showing the potential of using micromotors in vivo. (7A) Zn-micromotors propel in the acidic environment of mice stomach (i) enhancing their retention to the stomach wall via mucoadhesion. (ii) Micrographs, (iii) SEM and EDX analysis showing enhanced retention of the micromotors on the mice stomach. (iv) Inductively coupled plasma-mass spectrometry (ICP-MS) analysis highlighting AuNP retention $2 \mathrm{~h}$ after administration. (7B) pH-sensitive Mg-micromotors (i) effectively neutralize gastric acid for cargo release upon pH activation. (ii) Recovery of the gastric pH after treatments in mice $(\mathrm{n}=3)$ measured $20 \mathrm{~min}$ and $24 \mathrm{~h}$ post administration of $5 \mathrm{mg}$ of the Mg-micromotors. (iii) Superimposed fluorescent images of the whole stomach of mice collected 20 min post-administration of DI water, Mg-micromotors and inert PS microparticles (both DiDloaded within the $\mathrm{pH}$-sensitive polymer coating as model drug). (7C) Micromotors with enteric-coating towards site-specific drug delivery in GI tract via autonomous propulsion. (i) Schematic illustration of in vivo operation of the enteric Mg-micromotors (EMgMs) and snapshots showing their propulsion in intestinal fluid. (ii) Schematic of an EMgMs showing the loaded Mg microspheres and payload into PEDOT (green)/Au (yellow) microtubes coated with an enteric polymer (orange), and SEM imaging 
of the EMgMs. (iii) In vivo biodistribution and retention of EMgMs in the Gl tract using ICP-MS to determine of the number of micromotors with different enteric coating thickness (Mg micromotors without enteric coating, orange; EMgMs with thin, medium and thick polymer coating, red, blue and green respectively) retained in the stomach, duodenum, jejunum, and ileum $6 \mathrm{~h}$ post-oral administration. (iv) Superimposed fluorescent images of mouse Gl tracts at 6 and $12 \mathrm{~h}$ post-administration of EMgMs loaded with the dye Rhodamine 6G and covered with medium polymer coating. Reprinted (adapted) with permission from Wang et al. Enteric Micromotor Can Selectively Position and Spontaneously Propel in the Gastrointestinal Tract, ACS Nano. 10 (2016) $9536-9542$. doi:10.1021/acsnano.6b04795). Copyright (2016) American Chemical Society. (7D) Micromotor-enabled active drug delivery for in vivo treatment of stomach infection. (i) Schematic representation Mg-micromotors composition and their in vivo drug delivery. (ii) Bright-field and fluorescence images of the luminal lining of freshly excised mouse stomachs $2 \mathrm{~h}$ after oral gavage of the Mgbased micromotors. (iii) Study protocol and therapeutic outcome of CLR-delivery using micromotors stomach for the treatment of $H$. pylori infection. Image reproduced with permission from [92] [48][50]

While, thickness of mucus layer is highly variable $(40-200 \mu \mathrm{m})$ and any extra penetration may damage the underlying cells/tissues, swimming in such an environment is fairly 'difficult' owing to low Reynnold's number regime. [93] [94] While no actual drug was utilized in the above mentioned study, the $\mathrm{pH}$-sensitive drug release mechanism was demonstrated using $\mathrm{Au}$ nanoparticles,. It is advisable to demonstrate similar effect as a function of time so as to demonstrate enhanced retention of such mobile DDSs.[95]

Another key-area where these micromotors find merit is as an alternative for Proton Pump Inhibitor (PPI) drugs. PPIs are a class of drugs characterized by irreversible deactivation of the hydrogen-potassium adenosine triphosphatase enzyme system (commonly known as gastric proton pump), present on the lumen of parietal cells (responsible for $\mathrm{HCl}$ production), thereby, raising the gastroduodenal luminal $\mathrm{pH}$ from approximately 1.5 to 6.0. Similar to an antacid which neutralizes stomach acidity, these chemically propelled micromotors also react with the stomach acid to reduce its acidity. This is demonstrated by the reaction of stomach acid with alkali ions or acid hydrolysis in presence of metals, each effectively reducing the protons $\left(\mathrm{H}^{+}\right)$in the stomach.

However, PPIs have been questioned over their long term side-effects with reduced absorption of iron, calcium, magnesium zinc and vitamins (Vit B12).[96] [97][98] Interestingly, Mg and Zn 
have been used as an active layer (propellant) to react with the stomach acids, thereby simultaneously propelling the micromotors under in vivo conditions.[12,48,50,92] The choice of propellant becomes a relevant criteria (more than just propulsion), as severe hypomagnesaemia has been a challenge in long-term users of proton-pump inhibitors (PPIs), to which this study sheds new light by forming Mg-byproducts which can be absorbed by the body. [99][100] In fact, magnesium deficiency is not uncommon and $12 \%$ of patients admitted in hospitals (with $60-65 \%$ in Intensive Care Unit) have been diagnosed with hypomagnesemia.[101] Further, it should be noted that the inherent $\mathrm{H}_{2}$ gas production (upon reaction of $\mathrm{HCl}$ with $\mathrm{Zn}$ ) is a common feature of gut microflora activity and should not be of greater concern if within safe limits.[102] While one may argue that mode of action of a PPI is completely different than that of an antacid (to which this class of micromotors actually resembles more) the inherent novelty of such a design may actually be a clinically relevant idea which needs to be further investigated.

The intrinsic ability of chemically-propelled micromotors, to neutralize stomach acid in vivo (utilizing it as a local fuel), constitutes as a major improvement. This can be extrapolated in the field of clinical drug delivery to the Gl tract (harsh conditions), as many drugs suffer from very limited bioavailability.[103] Li et al. presented Mg-based Janus-like micromotors (figure 7B) that reacted spontaneously with the protons in the gastric acid to rapidly neutralize the stomach $\mathrm{pH}$ without affecting the normal stomach function. [48] The $\mathrm{pH}$-dependent release was demonstrated by fluorescent imaging (DiD dye) of the entire stomach confirmed homogeneous distribution along the entire tissue in the micromotors-treated mouse (figure 7B). To ensure that the normal stomach function was preserved after the treatment, recording stomach $\mathrm{pH}$ with a microelectrode sensor coupled with a pH meter was also carried out. Their results demonstrated that the neutral $\mathrm{pH} 7.81$ obtained $20 \mathrm{~min}$ after the micromotors administration returned back to $\mathrm{pH} 2.16$ within $24 \mathrm{~h}$ after treatments (figure $7 \mathrm{~B}$ ). However, care should be taken as single $\mathrm{pH}$ 
electrode measurements have demonstrated regional variation in four quartiles of the stomach.[104][105]

Another key-aspect of GI tract drug delivery is acknowledging the fact that different bacterial population (good or bad), colonize different segments of the Gl tract.[106] Several drugs need to pass through the stomach into duodenum and further for effective absorption . Therefore, there is a need to elucidate if these micromotors remain in the stomach, or can actually pass through pylorus to duodenum and beyond. In this regard, Li et al. (figure 7C) also demonstrated a smart way of shielding the activation of Mg-micromotors in the stomach ( $\mathrm{pH} 1-2)$ by incorporating an enteric coating around it. [49] These tubular micromotors were able to passively diffuse through the stomach and once reaching the intestine, the $\mathrm{pH}$-sensitive enteric protection exposed the underlying Mg microparticles, thereby activating the motors (via oxidation of $\mathrm{Mg}$ in water). This was confirmed by the ICP-MS analysis and fluorescent images of the mice Gl tract (6h after administration). Further, tuning the thickness of enteric coating facilitated micromotor propulsion into different parts of the GI tract including stomach, duodenum, jejunum and ileum (figure 7C).

The ability of these micromotors to effectively propel by reacting with its immediate biological environment (like stomach acid in GI tract), thereby reducing its local concentration becomes more relevant. Stomach infection with $H$. pylori has been reported as one of the main inducers of digestive tract disorders[107]. The ability of the bacteria to adhere to gastric mucosa and induce gastritis, a chronic inflammation of the mucosa, makes this condition particularly tricky to treat with conventional administration of antibiotics. Drug efficacy is further reduced owing to harsh acidic environment in the stomach and potential side-effects with prolong usage of PPIs[108]. To this end, a study done by Esteban-Fernández de Ávila et al. took a step forward and presented synthetic micromotors for actual drug delivery in vivo with an aim to evaluate their therapeutic potential to treat a disease. [50] Enhanced antibacterial efficacy was demonstrated with clarithromycin (CLR) loaded with Mg-micromotors against Helicobacter pylori 
stomach infection in mouse model. Mg-micromotors were prepared by coating Mg-microparticle core with a thin $\mathrm{TiO}_{2}$ film, followed with a layer PLGA-CLR matrix, and finally a positivelycharged surface coating of chitosan (figure 7D). Such a micromotor design configuration presents several advantages as follows: (i) exposed Mg-core generates a thrust of bubbles for propulsion (via oxidation of $\mathrm{Mg}$ in $\mathrm{H}_{2} \mathrm{O}$ ); (ii) simultaneously reducing the stomach $\mathrm{pH}$, creating favorable microenvironment for the drug; (iii) uni-directional propulsion promoting mucoadhesion followed by polymer swelling (in this case, chitosan) towards sustained-release of drug.

Further, CLR-Mg-micromotors also demonstrated greater penetration into the stomach mucosa, where $H$. pylori resides locally. The antibacterial activity of CLR-loaded Mg-micromotors was investigated in C57BL/6 mice infected with $H$. pylori treated every day during 5 consecutive days with $30 \mathrm{mg} / \mathrm{kg}$ of CLR drug either loaded within the motile Mg-micromotors, in silica microparticles as non-motile DDS and in free form combined with PPI omeprazole (conventional treatment to neutralize gastric acid in mice and preserve the effectivity of the co-administered antibiotics[109,110]). Results demonstrated moderate but significant reduction of $H$. pylori obtained by CLR-loaded Mg-micromotors compared to their non-motile control, the silica microparticles loaded with CLR (figure 7D), claiming that the active-propulsion was a key factor for the enhanced therapeutic outcome. In addition, while the antibacterial effect of Mgmicromotors and free CLR+PPI was similar, the oral treatment with CLR alone required prior administration of PPls to reduce the stomach $\mathrm{pH}$ for making the treatment effective. In this regard, the built-in proton depletion capacity of the Mg-micromotors offers unique ability to temporarily and reversibly neutralize the gastric $\mathrm{pH}$ and avoiding dependency on PPIs with all their potential side-effects.[111]

These unique properties actually place chemically-propelled micromotors (like Mg-micromotors) in a prominent position for alternative therapeutic strategies or combinatorial approach for 
oral/GI tract drug delivery. This becomes all the more relevant given the fact that $H$. pylori infection has been the single most cause of stomach ulcers often requiring PPI administration. Ironically, PPI administration in turn has also been cited as a causative agent for other enteric infections (Clostridium difficile) [112,113][114] While one may point to the inherent similarities between FDDS and micromotors for drug delivery, we strongly believe that these two distinct disciplines have excellent potential to work in synergy together.

\section{Can size and shape of micromotors affect their drug efficacy in vivo?}

Finally, as we discussed about size specification of micromotors, it is imperative to discuss size as well as shape related effects as in clinical DDS, which will be of considerable importance for the micromotors community. Shape and size of microparticulate DDS affects drug metabolism across all types of DDS. In fact, size influences almost every aspect of DDS ranging from degradation, flow properties, clearance and uptake mechanism. As their scale decreases, drug delivery devices may be delivered by ingestion $(\sim 1 \mathrm{~mm})$, injected into tissue $(<200 \mu \mathrm{m})$, inhaled $(<100 \mu \mathrm{m})$ or even released into circulation $(<10 \mu \mathrm{m})$.[115] This can be understood as particle size affects its diffusion and uptake in blood vessels, airways or GI tract. Microparticles of smaller size (1-5 $\mu \mathrm{m})$ are typically cleared out in the liver by Kupffer cells while larger particles are trapped in capillary beds.[116] In case of pulmonary administration, particle range of $\sim 3 \mu \mathrm{m}$ deposit deep in the alveolar region while large particles in upper airway (smaller particles exhaled).[117] Further, regardless of the method of administration, particles larger than $500 \mathrm{~nm}$ can be phagocytosed by macrophages while smaller particles can be cleared off via endocytosis.[118][119]

Even for imaging purposes, particle size is important. For example, one of the essential features of ultrasound contrast agent (UCA) is the size of the microcapsules. The agent must be smaller than $8 \mu \mathrm{m}$ in diameter for intravenous administration.[120] Interestingly, contrary to the belief that larger particles will experience more stearic hindrance, studies have indicated that despite 
the order-of-magnitude difference in bead diameters tested ( 0.02 to $2 \mu \mathrm{m})$, consistent delivery was achieved using US, showing no significant dependence on permeant size.[42]

Further, research into GI drug delivery systems has resulted in the development of several formulations including floating systems, mucoadhesive/bioadhesive systems, expandable systems and magnetic systems, all of which could prolong gastrointestinal (GI) residence time to improve drug effectiveness.[121] Reservoir-type microcapsules acting as drug microcontainers will be of considerable interest in this regard.[122] Owing to their sufficiently large internal volume $(100-250 \mu \mathrm{m})$ for drug loading, they have already demonstrated excellent pharmacological effects under in vivo setting.[103] [123][124] Similar design concepts may be tested with autonomous propulsion-external guidance.

Interestingly, there has been a renewed interest in shape related effects of DDS. A basic premise for it is the fact that drug release (Fick's law of diffusion) from the DDS can be controlled via uni- or omni-directional continuum of the carrier.[125] This can be understood by a study done by Langer et el. where they demonstrated zero-order release (which is the main goal of many sustained release formulations) with a hemispherical particle facilitating release from the face-end only.[126] This single-phase release feature has been highlighted as a significant advantage for top-down fabricated DDS without compromising on the continuum-like behavior. Therefore, polymer engineers and microfabrication experts have a common ground here in not only deciding the material but also the design aspects of these micromotors. Schoellhammer et al. demonstrated US mediated delivery of microparticles deep into colonic tissue ex vivo. [42] Delivery was relatively independent of size and charge but did depend on conformation, with regular, spherical particles being delivered to a greater extent than long-chain polymers. Finally, the shape of particle has also shown to have affected the immune cell response against them. Champion et el. demonstrated phagocytosis of PS shape (non-spherical, elongated ellipsoid) with rat alveolar macrophages and concluded that the local shape of the particle where the cell 
attached (not the overall shape) determined whether or not a macrophage began internalization.[127]

Much like a conventional DDS, externally actuated DDS are also disintegrated and cleared out by the body (mainly by kidneys and liver). Clearly, fabrication and administration of these micromotors should adhere to compounds/materials accepted as generally recognized as safe (GRAS).[128] This is where the choice of material and underlying chemical interfaces becomes very important. Metallic architecture employed is generally non-toxic (like Fe \& $\mathrm{Au}$ ) and is present in trace quantities (a few nm thick layer)[129], much like trace metals required by the body. For instance, Wu et al demonstrated protein-based drug micromotors can be completely biodegraded after enzymatic treatment under physiological conditions, thus suggesting limited in vivo toxicity.[130] Having said that, an in-depth toxicity and pharmacological assessment (including clearance) for micromotors has been long overdue.

\section{Conclusion}

Research presented here clearly demonstrate the suitability of micromotors towards drug delivery in vivo. After a decade's worth of research, the vanguard advances made in the area of micromotors is clearly observable. However, in order to successfully transition towards clinically relevant DDSs, it is imperative to identify and establish their pharmacokinetic and pharmacodynamic potentials. A key-issue in this regard could be significant infrastructure, as well as stringent ethical norms, that animal testing facilities require. Protocols required for such experiments are co-developed with clinicians and veterinarians on case by case basis. Since, micromotors in stomach promises to be a key-trend in the near future, one may explore an artificial stomach-duodenum model which is well established for in vitro studies with in vivo significance.[131][132] Biocompatibility of a DDS material is critical for any drug delivery from a pill or drug eluting devices. Given the broad range of such materials, relevant information can be 
looked up elsewhere.[133][134][135] Further, protein adsorption layer (protein corona) that forms on the surface of nano/microparticles plays an important role in their interaction with living matter.[136]

Another essential area of future research will rely on the ability to implement multiple exogenous elements over a single microparticle. As we can clearly see with US-NIR-magnetism, each technology has its own distinct set of advantages and a combinatorial approach will enable better theranostic systems in the future. Reservoir-type drug delivery systems will be of considerable importance as they not only load significantly high amounts of drugs but also can be used as ultrasound contrast agent (UCA).

A fundamental strength of micromotors under in vivo conditions has been its potential towards site-directed targeting (not entirely dependent on the circulation system). However, similar to conventional DDS, this should incorporate toxicity studies and associated immune response in vivo. Therefore, fundamental research in the area of better control and imaging modalities will continue to develop at a rapid rate to better support these demanding pharmacological benchmarks, most of which, for micromotors, will depend upon their motion properties.

While being a 'motor' certainly enhances some properties, in terms of drug delivery in vivo, microscale $(<100 \mu \mathrm{m})$ may find greater relevance towards delivery of APIs which are inherently required in rather low dosage other than conventional drugs (like hormones, enzymes, nucleic acids etc.). The tight interconnection between what can be termed as a nano/micromotor (including exogenous control schemes) and associated pharmacological benefits will expand the future of drug delivery. This will not be limited in terms of size-scale alone. 
Another newly emerging class of biogenic and bionic microsystems has also been tested for drug/cargo delivery applications both in vitro and in vivo.[137][138] While biogenic microsystems involve materials isolated from nature, bionic microsystems tag living cells (like sperm cells, mammalian and microbial cells) with advanced functionalities like drug transport.[137][139] A recent study by Martel et al.[140] is of particular significance here as they demonstrated magneto-aerotactic migration behavior of magnetotactic bacteria (Magnetococcus marinus MC1) towards a tumour for drug delivery in a mouse model. These bacteria were magnetically guided, resulting in enhanced penetration into hypoxic regions of HCT116 colorectal xenografts. An updated assessment of bioinspired microrobotics with different biological locomotion strategies can be looked elsewhere.[141][142]

The studies presented here not only discuss the advances made by micromotors in vivo but also provide a toolkit to further expand upon design-application relationship of these DDS. With interdisciplinary boundaries blurring fast, greater cooperation should be sought between disciplines even as diverse space or clean energy towards drug delivery applications.[143][144][145,146] Micromotors are here to stay (although, technically they move fast, really fast).

\section{ACKNOWLEDGEMENTS}

SKS would like to thank H.C. Ørsted COFUND for funding. SKS \& AB would like to acknowledge the Danish National Research Foundation (DNRF122) and Villum Fonden (Grant No. 9301) for Intelligent Drug Delivery and Sensing Using Microcontainers and Nanomechanics (IDUN). 


\section{REFERENCES}

[1] B.J. Bruno, G.D. Miller, C.S. Lim, Basics and recent advances in peptide and protein drug delivery, Ther. Deliv. 4 (2013) 1443-1467. doi:10.4155/tde.13.104.

[2] M. Dostalek, I. Gardner, B.M. Gurbaxani, R.H. Rose, M. Chetty, Pharmacokinetics, pharmacodynamics and physiologically-based pharmacokinetic modelling of monoclonal antibodies, Clin. Pharmacokinet. 52 (2013) 83-124. doi:10.1007/s40262-012-0027-4.

[3] L. Brunton, B. Chabner, B. Knollman, Goodman and Gilman's The Pharmacological Basis of Therapeutics, 2013. doi:10.1017/CBO9781107415324.004.

[4] S. Mitragotri, P.A. Burke, R. Langer, Overcoming the challenges in administering biopharmaceuticals: Formulation and delivery strategies, Nat. Rev. Drug Discov. 13 (2014) 655-672. doi:10.1038/nrd4363.

[5] M. Rowland, Influence of route of administration on drug availability, J. Pharm. Sci. 61 (1972) 70-74. doi:10.1002/jps.2600610111.

[6] T.M. Allen, P.R. Cullis, Drug Delivery Systems: Entering the Mainstream, Science (80-. ). 303 (2004) 1818-1822. doi:10.1126/science.1095833.

[7] M. Fantoni, C. Autore, C. Del Borgo, Drugs and cardiotoxicity in HIV and AIDS., Ann. N. Y. Acad. Sci. 946 (2001) 179-99. doi:10.1111/j.1749-6632.2001.tb03912.x.

[8] R.V.J. Chari, Targeted cancer therapy: Conferring specificity to cytotoxic drugs, Acc. Chem. Res. 41 (2008) 98-107. doi:10.1021/ar700108g. 
[9] W. Wang, W. Duan, Z. Zhang, M. Sun, A. Sen, T.E. Mallouk, A tale of two forces: simultaneous chemical and acoustic propulsion of bimetallic micromotors, Chem. Commun. 51 (2015) 1020-1023. doi:10.1039/C4CC09149C.

[10] D. Yamamoto, A. Shioi, Self-propelled nano/micromotors with a chemical reaction: Underlying physics and strategies of motion control, KONA Powder Part. J. (2015) 2-22. doi:10.14356/kona.2015005.

[11] F. Peng, Y. Tu, D.A. Wilson, Micro/nanomotors towards in vivo application: cell, tissue and biofluid, Chem. Soc. Rev. (2017). doi:10.1039/C6CS00885B.

[12] B. Esteban-Fernández de Ávila, P. Angsantikul, J. Li, W. Gao, L. Zhang, J. Wang, Micromotors Go In Vivo: From Test Tubes to Live Animals, Adv. Funct. Mater. (2017). doi:10.1002/adfm.201705640.

[13] K. Strebhardt, A. Ullrich, Paul Ehrlich 's magic bullet concept: 100 years of progress, Nat. Rev. Cancer. 8 (2008) 473-480. doi:10.1038/nrc2394.

[14] R.A. Bader, Fundamentals of Drug Delivery, in: Eng. Polym. Syst. Improv. Drug Deliv., 2013: pp. 1-28. doi:10.1002/9781118747896.ch1.

[15] H. Maeda, J. Wu, T. Sawa, Y. Matsumura, K. Hori, Tumor vascular permeability and the EPR effect in macromolecular therapeutics: A review, J. Control. Release. 65 (2000) 271-284. doi:10.1016/S0168-3659(99)00248-5.

[16] Y. Matsumura, M. Kimura, T. Yamamoto, H. Maeda, Involvement of the Kinin- generating Cascade in Enhanced Vascular Permeability in Tumor Tissue, Japanese J. Cancer Res. 79 (1988) 1327-1334. doi:10.1111/j.1349-7006.1988.tb01563.x.

[17] S. Bae, K. Ma, T.H. Kim, E.S. Lee, K.T. Oh, E.S. Park, K.C. Lee, Y.S. Youn, Doxorubicinloaded human serum albumin nanoparticles surface-modified with TNF-related apoptosis- 
inducing ligand and transferrin for targeting multiple tumor types, Biomaterials. 33 (2012) 1536-1546. doi:10.1016/j.biomaterials.2011.10.050.

[18] G.J. Tortora, B. Derrickson, Principles of Anatomy and Physiology, 2009.

[19] Y.S. Youn, Y.H. Bae, Perspectives on the past, present, and future of cancer nanomedicine, Adv. Drug Deliv. Rev. (2018). doi:10.1016/j.addr.2018.05.008.

[20] Y.H. Bae, K. Park, Targeted drug delivery to tumors: Myths, reality and possibility, J. Control. Release. 153 (2011) 198-205. doi:10.1016/j.jconrel.2011.06.001.

[21] S. Wilhelm, A.J. Tavares, Q. Dai, S. Ohta, J. Audet, H.F. Dvorak, W.C.W. Chan, Analysis of nanoparticle delivery to tumours, Nat. Rev. Mater. 1 (2016) 16014. doi:10.1038/natrevmats.2016.14.

[22] S.E. McNeil, Evaluation of nanomedicines: stick to the basics, Nat. Rev. Mater. 1 (2016) 16073. http://dx.doi.org/10.1038/natrevmats.2016.73.

[23] S. Wilhelm, A.J. Tavares, W.C.W. Chan, Reply to "Evaluation of nanomedicines: Stick to the basics," Nat. Rev. Mater. 1 (2016). doi:10.1038/natrevmats.2016.74.

[24] S. Gupta, R.J. Stafford, S. Javadi, E. Ozkan, J.E. Ensor, K.C. Wright, A.M. Elliot, Y. Jian, R.E. Serda, K.A. Dixon, J.J. Miller, S. Klump, M.J. Wallace, C. Li, Effects of near-infrared laser irradiation of biodegradable microspheres containing hollow gold nanospheres and paclitaxel administered intraarterially in a rabbit liver tumor model, J. Vasc. Interv. Radiol. 23 (2012) 553-561. doi:10.1016/j.jvir.2011.12.017.

[25] K. Fang, L. Song, Z. Gu, F. Yang, Y. Zhang, N. Gu, Magnetic field activated drug release system based on magnetic PLGA microspheres for chemo-thermal therapy, Colloids Surfaces B Biointerfaces. 136 (2015) 712-720. doi:10.1016/j.colsurfb.2015.10.014.

[26] S.K. Srivastava, M. Medina-Sánchez, B. Koch, O.G. Schmidt, Medibots: Dual-Action 
Biogenic Microdaggers for Single-Cell Surgery and Drug Release., Adv. Mater. 28 (2016) 832-7. doi:10.1002/adma.201504327.

[27] W. Gao, B.E.-F. de Ávila, L. Zhang, J. Wang, Targeting and isolation of cancer cells using micro/nanomotors, Adv. Drug Deliv. Rev. (2017).

doi:https://doi.org/10.1016/j.addr.2017.09.002.

[28] B. Esteban-Fernández De Ávila, C. Angell, F. Soto, M.A. Lopez-Ramirez, D.F. Báez, S. Xie, J. Wang, Y. Chen, Acoustically Propelled Nanomotors for Intracellular siRNA Delivery, ACS Nano. 10 (2016) 4997-5005. doi:10.1021/acsnano.6b01415.

[29] E. Gultepe, J.S. Randhawa, S. Kadam, S. Yamanaka, F.M. Selaru, E.J. Shin, A.N. Kalloo, D.H. Gracias, Biopsy with thermally-responsive untethered microtools, Adv. Mater. 25 (2013) 514-519. doi:10.1002/adma.201203348.

[30] H. Xu, M. Medina-Sánchez, V. Magdanz, L. Schwarz, F. Hebenstreit, O.G. Schmidt, Sperm-Hybrid Micromotor for Targeted Drug Delivery, ACS Nano. (2017) acsnano.7b06398. doi:10.1021/acsnano.7b06398.

[31] N. Fomina, J. Sankaranarayanan, A. Almutairi, Photochemical mechanisms of lighttriggered release from nanocarriers, Adv. Drug Deliv. Rev. 64 (2012) 1005-1020. doi:10.1016/j.addr.2012.02.006.

[32] D.Q.M. Craig, The mechanisms of drug release from solid dispersions in water-soluble polymers, Int. J. Pharm. 231 (2002) 131-144. doi:10.1016/S0378-5173(01)00891-2.

[33] J. Orozco, B. Jurado-Sánchez, G. Wagner, W. Gao, R. Vazquez-Duhalt, S. Sattayasamitsathit, M. Galarnyk, A. Cortés, D. Saintillan, J. Wang, Bubble-propelled micromotors for enhanced transport of passive tracers, Langmuir. 30 (2014) 5082-5087. doi:10.1021/la500819r. 
[34] S.K. Srivastava, O.G. Schmidt, Autonomously Propelled Motors for Value-Added Product Synthesis and Purification, Chem. - A Eur. J. 22 (2016) 9072-9076. doi:10.1002/chem.201600923.

[35] S.K. Srivastava, M. Medina-Sanchez, O.G. Schmidt, Autonomously propelled microscavengers for precious metal recovery, Chem. Commun. 53 (2017) 8140-8143. doi:10.1039/C7CC02605F.

[36] C. Gabriel, S. Gabriel, E. Corthout, The dielectric properties of biological tissues: I. Literature survey, Phys. Med. Biol. 41 (1996) 2231-2249. doi:10.1088/0031$9155 / 41 / 11 / 001$.

[37] S. Gabriel, R.W. Lau, C. Gabriel, The dielectric properties of biological tissues: II. Measurements in the frequency range $10 \mathrm{~Hz}$ to $20 \mathrm{GHz}$, Phys. Med. Biol. 41 (1996) 2251-2269. doi:10.1088/0031-9155/41/11/002.

[38] L.K. Wagner, P.J. Eifel, R.A. Geise, Potential biological effects following high X-ray dose interventional procedures., J. Vasc. Interv. Radiol. 5 (1994) 71-84. doi:10.1016/S10510443(94)71456-1.

[39] R. Deckers, C. Rome, C.T.W. Moonen, The role of ultrasound and magnetic resonance in local drug delivery., J. Magn. Reson. Imaging. 27 (2008) 400-9. doi:10.1002/jmri.21272.

[40] W. He, J. Frueh, N. Hu, L. Liu, M. Gai, Q. He, Guidable thermophoretic janus micromotors containing gold nanocolorifiers for infrared laser assisted tissue welding, Adv. Sci. 3 (2016). doi:10.1002/advs.201600206.

[41] Z. Zha, J. Wang, E. Qu, S. Zhang, Y. Jin, S. Wang, Z. Dai, Polypyrrole hollow microspheres as echogenic photothermal agent for ultrasound imaging guided tumor ablation, Sci. Rep. 3 (2013). doi:10.1038/srep02360. 
[42] C.M. Schoellhammer, Y. Chen, C. Cleveland, D. Minahan, T. Bensel, J.Y. Park, S. Saxton, Y.A.L. Lee, L. Booth, R. Langer, G. Traverso, Defining optimal permeant characteristics for ultrasound-mediated gastrointestinal delivery, J. Control. Release. 268 (2017) 113-119. doi:10.1016/j.jconrel.2017.10.023.

[43] B. Chertok, R. Langer, Circulating magnetic microbubbles for localized real-time control of drug delivery by ultrasonography-guided magnetic targeting and ultrasound, Theranostics. 8 (2018) 341-357. doi:10.7150/thno.20781.

[44] N. Butoescu, C.A. Seemayer, G. Palmer, P.A. Guerne, C. Gabay, E. Doelker, O. Jordan, Magnetically retainable microparticles for drug delivery to the joint: Efficacy studies in an antigen-induced arthritis model in mice, Arthritis Res. Ther. 11 (2009) 1-10. doi:10.1186/ar2701.

[45] A. Servant, F. Qiu, M. Mazza, K. Kostarelos, B.J. Nelson, Controlled in vivo swimming of a swarm of bacteria-like microrobotic flagella, Adv. Mater. 27 (2015) 2981-2988. doi:10.1002/adma.201404444.

[46] P. Pouponneau, J.C. Leroux, G. Soulez, L. Gaboury, S. Martel, Co-encapsulation of magnetic nanoparticles and doxorubicin into biodegradable microcarriers for deep tissue targeting by vascular MRI navigation, Biomaterials. 32 (2011) 3481-3486. doi:10.1016/j.biomaterials.2010.12.059.

[47] W. Gao, R. Dong, S. Thamphiwatana, J. Li, W. Gao, L. Zhang, J. Wang, Artificial Micromotors in the Mouse's Stomach: A Step toward in Vivo Use of Synthetic Motors, ACS Nano. 9 (2015) 117-123. doi:10.1021/nn507097k.

[48] J. Li, P. Angsantikul, W. Liu, B. Esteban-Fernández de Ávila, S. Thamphiwatana, M. Xu, E. Sandraz, X. Wang, J. Delezuk, W. Gao, L. Zhang, J. Wang, Micromotors Spontaneously Neutralize Gastric Acid for pH-Responsive Payload Release, Angew. 
Chemie - Int. Ed. 56 (2017) 2156-2161. doi:10.1002/anie.201611774.

[49] J. Li, S. Thamphiwatana, W. Liu, B. Esteban-Fernández De Ávila, P. Angsantikul, E. Sandraz, J. Wang, T. Xu, F. Soto, V. Ramez, X. Wang, W. Gao, L. Zhang, J. Wang, Enteric Micromotor Can Selectively Position and Spontaneously Propel in the Gastrointestinal Tract, ACS Nano. 10 (2016) 9536-9542. doi:10.1021/acsnano.6b04795.

[50] B.E.F. De Ávila, P. Angsantikul, J. Li, M. Angel Lopez-Ramirez, D.E. Ramírez-Herrera, S. Thamphiwatana, C. Chen, J. Delezuk, R. Samakapiruk, V. Ramez, L. Zhang, J. Wang, Micromotor-enabled active drug delivery for in vivo treatment of stomach infection, Nat. Commun. 8 (2017) 1-8. doi:10.1038/s41467-017-00309-w.

[51] Y. Cheng, A.C. Samia, J.D. Meyers, I. Panagopoulos, B. Fei, C. Burda, Highly efficient drug delivery with gold nanoparticle vectors for in vivo photodynamic therapy of cancer, J. Am. Chem. Soc. 130 (2008) 10643-10647. doi:10.1021/ja801631c.

[52] C. Alvarez-Lorenzo, L. Bromberg, A. Concheiro, Light-sensitive intelligent drug delivery systems, Photochem. Photobiol. 85 (2009) 848-860. doi:10.1111/j.17511097.2008.00530.x.

[53] J. Palacci, S. Sacanna, A. Vatchinsky, P.M. Chaikin, D.J. Pine, Photoactivated colloidal dockers for cargo transportation, J. Am. Chem. Soc. 135 (2013) 15978-15981. doi:10.1021/ja406090s.

[54] F. Martinez-Pedrero, H. Massana-Cid, P. Tierno, Assembly and Transport of Microscopic Cargos via Reconfigurable Photoactivated Magnetic Microdockers, Small. 13 (2017). doi:10.1002/smll.201603449.

[55] R. Weissleder, A clearer vision for in vivo imaging., Nat. Biotechnol. 19 (2001) 316-317. doi:10.1038/86684. 
[56] M.F. Bédard, B.G. De Geest, A.G. Skirtach, H. Möhwald, G.B. Sukhorukov, Polymeric microcapsules with light responsive properties for encapsulation and release, Adv. Colloid Interface Sci. 158 (2010) 2-14. doi:10.1016/j.cis.2009.07.007.

[57] A.M. Gobin, D.P. O'Neal, D.M. Watkins, N.J. Halas, R.A. Drezek, J.L. West, Near infrared laser-tissue welding using nanoshells as an exogenous absorber, Lasers Surg. Med. 37 (2005) 123-129. doi:10.1002/lsm.20206.

[58] D.S. Scherr, D.P. Poppas, Laser tissue welding, Urol. Clin. North Am. 25 (1998) 123135. doi:10.1016/S0094-0143(05)70439-0.

[59] L.S. Bass, M.R. Treat, Laser tissue welding: a comprehensive review of current and future clinical applications., Lasers Surg. Med. 17 (1995) 315-49. doi:10.1002/lsm.1900170402.

[60] H. Ke, J. Wang, Z. Dai, Y. Jin, E. Qu, Z. Xing, C. Guo, X. Yue, J. Liu, Gold-nanoshelled microcapsules: A theranostic agent for ultrasound contrast imaging and photothermal therapy, Angew. Chemie - Int. Ed. 50 (2011) 3017-3021. doi:10.1002/anie.201008286.

[61] J. Wang, Cargo-towing synthetic nanomachines: Towards active transport in microchip devices, Lab Chip. 12 (2012) 1944. doi:10.1039/c2lc00003b.

[62] S. Sundararajan, S. Sengupta, M.E. Ibele, A. Sen, Drop-off of colloidal cargo transported by catalytic Pt-Au nanomotors via photochemical stimuli, Small. 6 (2010) 1479-1482. doi:10.1002/smll.201000227.

[63] J.Y. Hong, H. Yoon, J. Jang, Kinetic study of the formation of polypyrrole nanoparticles in water-soluble polymer/metal cation systems: A light-scattering analysis, Small. 6 (2010) 679-686. doi:10.1002/smll.200902231.

[64] P.M. George, A.W. Lyckman, D.A. Lavan, A. Hegde, Y. Leung, R. Avasare, C. Testa, 
P.M. Alexander, R. Langer, M. Sur, Fabrication and biocompatibility of polypyrrole implants suitable for neural prosthetics, Biomaterials. 26 (2005) 3511-3519. doi:10.1016/j.biomaterials.2004.09.037.

[65] W.G. Pitt, G.A. Husseini, B.J. Staples, Ultrasonic drug delivery--a general review., Expert Opin. Drug Deliv. 1 (2004) 37-56. doi:10.1517/17425247.1.1.37.

[66] K.W. Ferrara, Driving delivery vehicles with ultrasound, Adv. Drug Deliv. Rev. 60 (2008) 1097-1102. doi:10.1016/j.addr.2008.03.002.

[67] L.A. Crum, J.B. Fowlkes, Acoustic cavitation generated by microsecond pulses of ultrasound, Nature. 319 (1986) 52-54. doi:10.1038/319052a0.

[68] D. Vilela, U. Cossío, J. Parmar, V. Gómez-Vallejo, A.M. Martínez, J. Llop, S. Sanchez, Medical Imaging for the Tracking of Micromotors, ACS Nano. (2018) acsnano.7b07220. doi:10.1021/acsnano.7b07220.

[69] C.M. Schoellhammer, A. Schroeder, R. Maa, G.Y. Lauwers, A. Swiston, M. Zervas, R. Barman, A.M. DiCiccio, W.R. Brugge, D.G. Anderson, D. Blankschtein, R. Langer, G. Traverso, Ultrasound-mediated gastrointestinal drug delivery, Sci. Transl. Med. 7 (2015). doi:10.1126/scitranslmed.aaa5937.

[70] B.E. Polat, D. Hart, R. Langer, D. Blankschtein, Ultrasound-mediated transdermal drug delivery: Mechanisms, scope, and emerging trends, J. Control. Release. 152 (2011) 330348. doi:10.1016/j.jconrel.2011.01.006.

[71] C.M. Schoellhammer, G.Y. Lauwers, J.A. Goettel, M.A. Oberli, C. Cleveland, J.Y. Park, D. Minahan, Y. Chen, D.G. Anderson, A. Jaklenec, S.B. Snapper, R. Langer, G. Traverso, Ultrasound-Mediated Delivery of RNA to Colonic Mucosa of Live Mice, Gastroenterology. 152 (2017) 1151-1160. doi:10.1053/j.gastro.2017.01.002. 
[72] G.C. Hansson, Role of mucus layers in gut infection and inflammation, Curr. Opin. Microbiol. 15 (2012) 57-62. doi:10.1016/j.mib.2011.11.002.

[73] X. Wang, A.K. Searle, J.D. Hohmann, A.L. Liu, M.-K. Abraham, J. Palasubramaniam, B. Lim, Y. Yao, M. Wallert, E. Yu, Y.-C. Chen, K. Peter, Dual-Targeted Theranostic Delivery of miRs Arrests Abdominal Aortic Aneurysm Development, Mol. Ther. (2018). doi:https://doi.org/10.1016/j.ymthe.2018.02.010.

[74] Y. Morimoto, K. Sugibayashi, M. Okumura, Y. Kato, Biomedical applications of magnetic fluids. I. Magnetic guidance of ferro-colloid-entrapped albumin microsphere for site specific drug delivery in vivo, J. Pharmacobiodyn. 3 (1980) 264-267. doi:10.1248/bpb1978.3.264.

[75] R. Dreyfus, J. Baudry, M.L. Roper, M. Fermigier, H. a Stone, J. Bibette, Microscopic artificial swimmers, Nature. 437 (2005) 862-865. doi:10.1038/nature04090.

[76] N. Butoescu, O. Jordan, P. Burdet, P. Stadelmann, A. Petri-Fink, H. Hofmann, E. Doelker, Dexamethasone-containing biodegradable superparamagnetic microparticles for intra-articular administration: Physicochemical and magnetic properties, in vitro and in vivo drug release, Eur. J. Pharm. Biopharm. 72 (2009) 529-538. doi:10.1016/j.ejpb.2009.03.003.

[77] D.N. Price, L.R. Stromberg, N.K. Kunda, P. Muttil, In Vivo Pulmonary Delivery and Magnetic-Targeting of Dry Powder Nano-in-Microparticles, Mol. Pharm. 14 (2017) 47414750. doi:10.1021/acs.molpharmaceut.7b00532.

[78] S.K. Srivastava, M. Guix, O.G. Schmidt, Wastewater Mediated Activation of Micromotors for Efficient Water Cleaning, Nano Lett. 16 (2016) 817-821. doi:10.1021/acs.nanolett.5b05032. 
[79] W.F. Paxton, S. Sundararajan, T.E. Mallouk, A. Sen, Chemical locomotion, Angew. Chemie - Int. Ed. 45 (2006) 5420-5429. doi:10.1002/anie.200600060.

[80] B.N. Singh, K.H. Kim, Floating drug delivery systems: An approach to oral controlled drug delivery via gastric retention, J. Control. Release. 63 (2000) 235-259. doi:10.1016/S0168-3659(99)00204-7.

[81] Y. Kawashima, T. Niwa, H. Takeuchi, T. Hino, Y. Itoh, Hollow microspheres for use as a floating controlled drug delivery system in the stomach, J. Pharm. Sci. 81 (1992) 135140. doi:10.1002/jps.2600810207.

[82] M. Manjare, B. Yang, Y.P. Zhao, Bubble driven quasioscillatory translational motion of catalytic micromotors, Phys. Rev. Lett. 109 (2012).

doi:10.1103/PhysRevLett.109.128305.

[83] A.A. Solovev, Y. Mei, E.B. Ureña, G. Huang, O.G. Schmidt, Catalytic microtubular jet engines self-propelled by accumulated gas bubbles, Small. 5 (2009) 1688-1692. doi:10.1002/smll.200900021.

[84] N. Lindberg, H. Hansson, Effervescent pharmaceuticals, Encycl. Pharm. .... (2002) 1037-1049. doi:10.1081/E-EPT-100000991.

[85] Y. Yun, Z. Dong, N. Lee, Y. Liu, D. Xue, X. Guo, J. Kuhlmann, A. Doepke, H.B. Halsall, W. Heineman, S. Sundaramurthy, M.J. Schulz, Z. Yin, V. Shanov, D. Hurd, P. Nagy, W. Li, C. Fox, Revolutionizing biodegradable metals, Mater. Today. 12 (2009) 22-32. doi:10.1016/S1369-7021(09)70273-1.

[86] N. Özdemir, S. Ordu, Y. Özkan, Studies of floating dosage forms of furosemide: In vitro and in vivo evaluations of bilayer tablet formulations, Drug Dev. Ind. Pharm. 26 (2000) 857-866. doi:10.1081/DDC-100101309. 
[87] S. Arora, J. Ali, A. Ahuja, R.K. Khar, S. Baboota, Floating drug delivery systems: A review, AAPS PharmSciTech. 6 (2005) E372-E390. doi:10.1208/pt060347.

[88] Y. Akiyama, N. Nagahara, E. Nara, M. Kitano, S. Iwasa, I. Yamamoto, J. Azuma, Y. Ogawa, Evaluation of oral mucoadhesive microspheres in man on the basis of the pharmacokinetics of furosemide and riboflavin, compounds with limited gastrointestinal absorption sites, J. Pharm. Pharmacol. 50 (1998) 159-166. doi:10.1111/j.20427158.1998.tb06171.x.

[89] M.R. Jiménez-Castellanos, H. Zia, C.T. Rhodes, Design and testing in vitro of a bioadhesive and floating drug delivery system for oral application, Int. J. Pharm. 105 (1994) 65-70. doi:10.1016/0378-5173(94)90236-4.

[90] A. Streubel, J. Siepmann, R. Bodmeier, Gastroretentive drug delivery systems, Expert Opin. Drug Deliv. 3 (2006) 217-233. doi:10.1517/17425247.3.2.217.

[91] S. Shah, R. Qaqish, V. Patel, M. Amiji, Evaluation of the Factors Influencing Stomachspecific Delivery of Antibacterial Agents for Helicobacter pylori Infection, J. Pharm. Pharmacol. 51 (1999) 667-672. doi:10.1211/0022357991772952.

[92] W. Gao, R. Dong, S. Thamphiwatana, J. Li, W. Gao, L. Zhang, J. Wang, Artificial Micromotors in the Mouse's Stomach: A Step toward in Vivo Use of Synthetic Motors, ACS Nano. 9 (2014) 117-123.

[93] C. Atuma, V. Strugala, A. Allen, L. Holm, The adherent gastrointestinal mucus gel layer: thickness and physical state in vivo, Am. J. Physiol. Liver Physiol. 280 (2001) G922G929. doi:10.1152/ajpgi.2001.280.5.G922.

[94] E. Purcell, Life at low Reynolds number, Am. J. Phys. 45 (1977) 3. doi:10.1119/1.10903.

[95] R.P. Singh, D.S. Rathore, Gastroretention: a means to address local targetting in the 
gastric region., Pharmacophore. 3 (2012) 287-300.

[96] T. Ito, R.T. Jensen, Association of long-term proton pump inhibitor therapy with bone fractures and effects on absorption of calcium, vitamin B12, iron, and magnesium, Curr. Gastroenterol. Rep. 12 (2010) 448-457. doi:10.1007/s11894-010-0141-0.

[97] C.P. Farrell, M. Morgan, D.S. Rudolph, A. Hwang, N.E. Albert, M.C. Valenzano, X. Wang, G. Mercogliano, J.M. Mullin, Press Elmer Proton Pump Inhibitors Interfere With Zinc Absorption and Zinc Body Stores, Gastroenterol. Res. @BULLET. 4 (2011) 243-251. doi:10.4021/gr379w.

[98] M.J. Salgueiro, M. Zubillaga, A. Lysionek, M.I. Sarabia, R. Caro, T. De Paoli, A. Hager, R. Weill, J. Boccio, Zinc as an essential micronutrient: A review, Nutr. Res. 20 (2000) 737755. doi:10.1016/S0271-5317(00)00163-9.

[99] T. Cundy, A. Dissanayake, Severe hypomagnesaemia in long-term users of proton-pump inhibitors, Clin. Endocrinol. (Oxf). 69 (2008) 338-341. doi:10.1111/j.13652265.2008.03194.x.

[100] E.J. Hoorn, J. van der Hoek, R.A. de Man, E.J. Kuipers, C. Bolwerk, R. Zietse, A Case Series of Proton Pump Inhibitor-Induced Hypomagnesemia, Am. J. Kidney Dis. 56 (2010) 112-116. doi:10.1053/j.ajkd.2009.11.019.

[101] Z.S. Agus, Mechanisms and causes of hypomagnesemia, Curr. Opin. Nephrol. Hypertens. 25 (2016) 301-307. doi:10.1097/MNH.0000000000000238.

[102] J. Jahng, I.S. Jung, E.J. Choi, J.L. Conklin, H. Park, The effects of methane and hydrogen gases produced by enteric bacteria on ileal motility and colonic transit time, Neurogastroenterol. Motil. 24 (2012). doi:10.1111/j.1365-2982.2011.01819.x.

[103] C. Mazzoni, F. Tentor, S.A. Strindberg, L.H. Nielsen, S.S. Keller, T.S. Alstrøm, C. 
Gundlach, A. Müllertz, P. Marizza, A. Boisen, From concept to in vivo testing:

Microcontainers for oral drug delivery, J. Control. Release. 268 (2017) 343-351. doi:10.1016/j.jconrel.2017.10.013.

[104] R.S. Fisher, D.J. Sher, D. Donahue, L.C. Knight, A. Maurer, J.L. Urbain, B. Krevsky, Regional differences in gastric acidity and antacid distribution: is a single $\mathrm{pH}$ electrode sufficient?, Am. J. Gastroenterol. 92 (1997) 263-70.

[105] M.A. van Herwaarden, M. Samsom, A.J. Smout, 24-h recording of intragastric pH: technical aspects and clinical relevance., Scand. J. Gastroenterol. Suppl. 230 (1999) 916. doi:10.1080/003655299750025219.

[106] N. Kamada, S.U. Seo, G.Y. Chen, G. Núñez, Role of the gut microbiota in immunity and inflammatory disease, Nat. Rev. Immunol. 13 (2013) 321-335. doi:10.1038/nri3430.

[107] T. Ito, D. Kobayashi, K. Uchida, T. Takemura, S. Nagaoka, I. Kobayashi, T. Yokoyama, I. Ishige, Y. Ishige, N. Ishida, A. Furukawa, H. Muraoka, S. Ikeda, M. Sekine, N. Ando, Y. Suzuki, T. Yamada, T. Suzuki, Y. Eishi, Helicobacter pylori invades the gastric mucosa and translocates to the gastric lymph nodes, Lab. Investig. 88 (2008) 664-681. doi:10.1038/labinvest.2008.33.

[108] P. Moayyedi, G.I. Leontiadis, The risks of PPI therapy, Nat. Rev. Gastroenterol. Hepatol. 9 (2012) 132-139. doi:10.1038/nrgastro.2011.272.

[109] S. Thamphiwatana, W. Gao, M. Obonyo, L. Zhang, In vivo treatment of Helicobacter pylori infection with liposomal linolenic acid reduces colonization and ameliorates inflammation, Proc. Natl. Acad. Sci. 111 (2014) 17600-17605. doi:10.1073/pnas.1418230111.

[110] C.D. Tran, S. Kritas, M.A.F. Campbell, H.Q. Huynh, S.S. Lee, R.N. Butler, Novel 
combination therapy for the eradication of Helicobacter pylori infection in a mouse model, Scand. J. Gastroenterol. 45 (2010) 1424-1430. doi:10.3109/00365521.2010.506245.

[111] Y. Xie, B. Bowe, T. Li, H. Xian, Y. Yan, Z. Al-Aly, Risk of death among users of Proton Pump Inhibitors: A longitudinal observational cohort study of United States veterans, BMJ Open. 7 (2017) 1-11. doi:10.1136/bmjopen-2016-015735.

[112] H. Suzuki, H. Mori, Helicobacter pylori: Helicobacter pylori gastritis--a novel distinct disease entity., Nat. Rev. Gastroenterol. Hepatol. 12 (2015) 556-7. doi:10.1038/nrgastro.2015.158.

[113] C.W. Howden, R.H. Hunt, Guidelines for the management of Helicobacter pylori infection, Am. J. Gastroenterol. 93 (1998) 2330-2338. doi:10.1016/S0002-9270(98)00565-6.

[114] J. Leonard, J.K. Marshall, P. Moayyedi, Systematic review of the risk of enteric infection in patients taking acid suppression, Am. J. Gastroenterol. 102 (2007) 2047-2056. doi:10.1111/j.1572-0241.2007.01275.x.

[115] D.A. LaVan, T. McGuire, R. Langer, Small-scale systems for in vivo drug delivery, Nat. Biotechnol. 21 (2003) 1184-1191. doi:10.1038/nbt876.

[116] L. Ilium, S.S. Davis, C.G. Wilson, N.W. Thomas, M. Frier, J.G. Hardy, Blood clearance and organ deposition of intravenously administered colloidal particles. The effects of particle size, nature and shape, Int. J. Pharm. 12 (1982) 135-146. doi:10.1016/03785173(82)90113-2.

[117] D.A. Edwards, J. Hanes, G. Caponetti, J. Hrkach, A. Ben-Jebria, M. Lou Eskew, J. Mintzes, D. Deaver, N. Lotan, R. Langer, Large porous particles for pulmonary drug delivery, Science (80-. ). 276 (1997) 1868-1871. doi:10.1126/science.276.5320.1868.

[118] W.L.L. Suen, Y. Chau, Size-dependent internalisation of folate-decorated nanoparticles 
via the pathways of clathrin and caveolae-mediated endocytosis in ARPE-19 cells, J. Pharm. Pharmacol. 66 (2014) 564-573. doi:10.1111/jphp.12134.

[119] R.C. May, L.M. Machesky, Phagocytosis and the actin cytoskeleton., J. Cell Sci. 114 (2001) 1061-1077.

[120] Z. Xing, H. Ke, J. Wang, B. Zhao, X. Yue, Z. Dai, J. Liu, Novel ultrasound contrast agent based on microbubbles generated from surfactant mixtures of Span 60 and polyoxyethylene 40 stearate, Acta Biomater. 6 (2010) 3542-3549. doi:10.1016/j.actbio.2010.03.007.

[121] P.L. Bardonnet, V. Faivre, W.J. Pugh, J.C. Piffaretti, F. Falson, Gastroretentive dosage forms: Overview and special case of Helicobacter pylori, J. Control. Release. 111 (2006) 1-18. doi:10.1016/j.jconrel.2005.10.031.

[122] H. Ichikawa, Y. Fukumori, A novel positively thermosensitive controlled-release microcapsule with membrane of nano-sized poly( $\mathrm{N}$-isopropylacrylamide) gel dispersed in ethylcellulose matrix, J. Control. Release. 63 (2000) 107-119. doi:10.1016/S01683659(99)00181-9.

[123] P. Marizza, S.S. Keller, A. Müllertz, A. Boisen, Polymer-filled microcontainers for oral delivery loaded using supercritical impregnation, J. Control. Release. 173 (2014) 1-9. doi:10.1016/j.jconrel.2013.09.022.

[124] L.H. Nielsen, A. Melero, S.S. Keller, J. Jacobsen, T. Garrigues, T. Rades, A. Müllertz, A. Boisen, Polymeric microcontainers improve oral bioavailability of furosemide, Int. J. Pharm. 504 (2016) 98-109. doi:10.1016/j.jpharm.2016.03.050.

[125] J. Siepmann, F. Siepmann, Modeling of diffusion controlled drug delivery, J. Control. Release. 161 (2012) 351-362. doi:10.1016/j.jconrel.2011.10.006. 
[126] D.S.T. Hsieh, W.D. Rhine, R. Langer, Zero-order controlled-release polymer matrices for micro- and macromolecules, J. Pharm. Sci. 72 (1983) 17-22.

doi:10.1002/jps.2600720105.

[127] J.A. Champion, Y.K. Katare, S. Mitragotri, Particle shape: A new design parameter for micro- and nanoscale drug delivery carriers, J. Control. Release. 121 (2007) 3-9. doi:10.1016/j.jconrel.2007.03.022.

[128] A. Cobo, R. Sheybani, E. Meng, MEMS: Enabled Drug Delivery Systems, Adv. Healthc. Mater. 4 (2015) 969-982. doi:10.1002/adhm.201400772.

[129] P.P. Karmali, D. Simberg, Interactions of nanoparticles with plasma proteins: implication on clearance and toxicity of drug delivery systems, Expert Opin. Drug Deliv. 8 (2011) 343-357. doi:10.1517/17425247.2011.554818.

[130] Z. Wu, X. Lin, X. Zou, J. Sun, Q. He, Biodegradable protein-based rockets for drug transportation and light-triggered release, ACS Appl. Mater. Interfaces. 7 (2015) 250255. doi:10.1021/am507680u.

[131] J. Vatier, A. Harman, N. Castela, M.T. Droy-Lefaix, R. Farinotti, Interactions of cimetidine and ranitidine with aluminum-containing antacids and a clay-containing gastric-protective drug in an "artificial stomach-duodenum" model, J. Pharm. Sci. 83 (1994) 962-966. doi:10.1002/jps.2600830709.

[132] S. Blanquet, E. Zeijdner, E. Beyssac, J.P. Meunier, S. Denis, R. Havenaar, M. Alric, A dynamic arificial gastrointestinal system for studying the behavior of orally administrated drug dosage forms under various physiological conditions, Pharm. Res. 21 (2004) 585591. doi:10.1023/B:PHAM.0000022404.70478.4b.

[133] Y. Lu, A.A. Aimetti, R. Langer, Z. Gu, Bioresponsive materials, Nat. Rev. Mater. 2 (2016). 
doi:10.1038/natrevmats.2016.75.

[134] S.Y. Chin, Y.C. Poh, A.-C. Kohler, J.T. Compton, L.L. Hsu, K.M. Lau, S. Kim, B.W. Lee, F.Y. Lee, S.K. Sia, Additive manufacturing of hydrogel-based materials for nextgeneration implantable medical devices, Sci. Robot. 2 (2017) eaah6451. doi:10.1126/scirobotics.aah6451.

[135] E.J. Lee, B.K. Huh, S.N. Kim, J.Y. Lee, C.G. Park, A.G. Mikos, Y. Bin Choy, Application of materials as medical devices with localized drug delivery capabilities for enhanced wound repair, Prog. Mater. Sci. 89 (2017) 392-410. doi:10.1016/j.pmatsci.2017.06.003.

[136] P. Del Pino, B. Pelaz, Q. Zhang, P. Maffre, G.U. Nienhaus, W.J. Parak, Protein corona formation around nanoparticles - From the past to the future, Mater. Horizons. 1 (2014) 301-313. doi:10.1039/c3mh00106g.

[137] S.K. Srivastava, M. Medina-Sánchez, B. Koch, O.G. Schmidt, Medibots: Dual-Action Biogenic Microdaggers for Single-Cell Surgery and Drug Release, Adv. Mater. (2015) n/a-n/a. doi:10.1002/adma.201504327.

[138] M. Stanton, B. Park, A. Miguel-López, X. Ma, M. Sitti, S. Sánchez, Biohybrid microtube swimmers driven by single captured bacteria, Small. 13 (2017) 1603679.

[139] S.K. Srivastava, V.G. Yadav, Bionic Manufacturing: Towards Cyborg Cells and Sentient Microbots, Trends Biotechnol. (2017). doi:10.1016/j.tibtech.2017.11.002.

[140] O. Felfoul, M. Mohammadi, S. Taherkhani, D. De Lanauze, Y. Zhong Xu, D. Loghin, S. Essa, S. Jancik, D. Houle, M. Lafleur, L. Gaboury, M. Tabrizian, N. Kaou, M. Atkin, T. Vuong, G. Batist, N. Beauchemin, D. Radzioch, S. Martel, Magneto-aerotactic bacteria deliver drug-containing nanoliposomes to tumour hypoxic regions, Nat. Nanotechnol. 11 (2016) 941-947. doi:10.1038/nnano.2016.137. 
[141] S. Palagi, P. Fischer, Bioinspired microrobots, Nat. Rev. Mater. 3 (2018) 113-124. doi:10.1038/s41578-018-0016-9.

[142] M. Sitti, Miniature soft robots - road to the clinic, Nat. Rev. Mater. 3 (2018) 74-75. doi:10.1038/s41578-018-0001-3.

[143] D.L. Hitt, C.M. Zakrzwski, M.A. Thomas, MEMS-based satellite micropropulsion via catalyzed hydrogen peroxide decomposition, Smart Mater. Struct. 10 (2001) 1163-1175. doi:10.1088/0964-1726/10/6/305.

[144] W. Zou, C. Visser, J.A. Maduro, M.S. Pshenichnikov, J.C. Hummelen, Broadband dyesensitized upconversion of near-infrared light, Nat. Photonics. 6 (2012) 560-564. doi:10.1038/nphoton.2012.158.

[145] N.M. Idris, M.K. Gnanasammandhan, J. Zhang, P.C. Ho, R. Mahendran, Y. Zhang, In vivo photodynamic therapy using upconversion nanoparticles as remote-controlled nanotransducers, Nat. Med. 18 (2012) 1580-1585. doi:10.1038/nm.2933.

[146] B.M. van der Ende, L. Aarts, A. Meijerink, Lanthanide ions as spectral converters for solar cells, Phys. Chem. Chem. Phys. 11 (2009) 11081. doi:10.1039/b913877c. 